\title{
Regulation of Lateral Hypothalamic Orexin Activity by Local GABAergic Neurons
}

\author{
Loris L. Ferrari, ${ }^{1}{ }^{-D}$ Daniel Park, ${ }^{1}$ Lin Zhu, ${ }^{1}{ }^{\circledR}$ Matthew R. Palmer, ${ }^{2}$ Rebecca Y. Broadhurst, ${ }^{1}$ and ${ }^{\odot E l d a ~ A r r i g o n i ~}{ }^{1}$ \\ ${ }^{1}$ Department of Neurology and ${ }^{2}$ Department of Radiology, Beth Israel Deaconess Medical Center, Boston, Massachusetts 02215
}

Orexin (also known as hypocretin) neurons are considered a key component of the ascending arousal system. They are active during wakefulness, at which time they drive and maintain arousal, and are silent during sleep. Their activity is controlled by long-range inputs from many sources, as well as by more short-range inputs, including from presumptive GABAergic neurons in the lateral hypothalamus/ perifornical region (LH/PF). To characterize local GABAergic input to orexin neurons, we used channelrhodopsin-2-assisted circuit mapping in brain slices. We expressed channelrhodopsin-2 in GABAergic neurons $\left(\mathrm{Vgat}^{+}\right.$) in the LH/PF and recorded from genetically identified surrounding orexin neurons $\left(\mathrm{LH} / \mathrm{PF}^{\text {Vgat }} \rightarrow\right.$ Orx). We performed all experiments in mice of either sex. Photostimulation of $\mathrm{LH} / \mathrm{PF}$ GABAergic neurons inhibited the firing of orexin neurons through the release of GABA, evoking $\mathrm{GABA}_{\mathrm{A}}$-mediated IPSCs in orexin neurons. These photo-evoked IPSCs were maintained in the presence of TTX, indicating direct connectivity. Carbachol inhibited LH/ $\mathrm{PF}^{\mathrm{Vgat}} \rightarrow$ Orx input through muscarinic receptors. By contrast, application of orexin was without effect on $\mathrm{LH} / \mathrm{PF}^{\mathrm{Vgat}} \rightarrow$ Orx input, whereas dynorphin, another peptide produced by orexin neurons, inhibited $\mathrm{LH} / \mathrm{PF}^{\mathrm{Vgat}} \rightarrow$ Orx input through $\kappa$-opioid receptors. Our results demonstrate that orexin neurons are under inhibitory control by local GABAergic neurons and that this input is depressed by cholinergic signaling, unaffected by orexin and inhibited by dynorphin. We propose that local release of dynorphin may, via collaterals, provides a positive feedback to orexin neurons and that, during wakefulness, orexin neurons may be disinhibited by acetylcholine and by their own release of dynorphin.

Key words: channelrhodopsin-2 (ChR2) assisted circuit mapping; electrophysiology; GABA; hypocretin; mice; orexin

\section{Significance Statement}

The lateral hypothalamus contains important wake-promoting cell populations, including orexin-producing neurons. Intermingled with the orexin neurons, there are other cell populations that selectively discharge during nonrapid eye movement or rapid eye movement sleep. Some of these sleep-active neurons release GABA and are thought to inhibit wake-active neurons during rapid eye movement and nonrapid eye movement sleep. However, this hypothesis had not been tested. Here we show that orexin neurons are inhibited by a local GABAergic input. We propose that this local GABAergic input inhibits orexin neurons during sleep but that, during wakefulness, this input is depressed, possibly through cholinergically mediated disinhibition and/or by release of dynorphin from orexin neurons themselves.

\section{Introduction}

Orexin (also called hypocretin) neurons play an essential role in wake maintenance. Selective loss of orexin-producing neurons in

\footnotetext{
Received July 3, 2017; revised Dec. 4, 2017; accepted Dec. 27, 2017

Author contributions: L.F.F. and E.A. designed research; L.F.F., D.P., L.Z., and R.Y.B. performed research; L.F.F., L.Z., M.R.P., and E.A. analyzed data; E.A. wrote the paper.

This work was supported by National Institutes of Health Grants 1R01NS091126 and 2P01HL095491. We thank Dr. Roberto De Luca for helping with the confocal imaging; and Dr. Patrick M. Fuller for critically reading the manuscript and for many helpful suggestions.

The authors declare no competing financial interests.

Correspondence should be addressed to Dr. Elda Arrigoni, Department of Neurology, Beth Israel Deaconess

Medical Center, 3 Blackfan Circle, Center for Life Science, Room 713, Boston, MA 02215. E-mail: earrigon@bidmc.harvard.edu.

DOI:10.1523/JNEUROSCI.1925-17.2017

Copyright $\odot 2018$ the authors $\quad 0270-6474 / 18 / 381588-12 \$ 15.00 / 0$
}

humans, as occurs in narcolepsy (Blouin et al., 2005; Crocker et al., 2005), results in chronic daytime sleepiness, which can interfere with the ability of narcopleptics to remain attentive in school, work, or while driving (Scammell, 2015). Disruption of orexin signaling in mice, rats, and dogs produces a very similar phenotype, including short bouts of wake and frequent transitions between behavioral states (Chemelli et al., 1999; Mochizuki et al., 2004).

Orexin neurons are wake-active, wake-promoting, fire maximally during wake, and extracellular levels of orexin are highest during wakefulness (Kiyashchenko et al., 2002; Lee et al., 2005). The firing rate of orexin neurons also increases during periods of movements and explorative behaviors, whereas they are mostly silent in nonrapid eye movement (NREM) and rapid eye move- 
ment (REM) sleep (Lee et al., 2005; Mileykovskiy et al., 2005), although occasional discharges are observed during REM sleep when small movements or twitches occur (Lee et al., 2005; Mileykovskiy et al., 2005). Optogenetic and chemogenetic activation of the orexin neurons rouses mice from sleep, prolongs wakefulness, and strongly suppresses REM sleep (Adamantidis et al., 2007; Sasaki et al., 2011). Similarly, intraventricular injection of orexin produces long periods of wakefulness and suppresses REM sleep for several hours (Mieda et al., 2011).

Our understanding of how orexin neurons and their activity is regulated remains incompletely understood. However, several lines of evidence suggest that, during NREM and REM sleep, orexin neuronal activity may be suppressed by inhibitory GABAergic inputs. For example, GABA release in the posterior hypothalamus is higher during NREM and REM sleep (Nitz and Siegel, 1996), and injection of the GABA antagonist bicuculline during the light-on (or sleep) period induces cFos expression in orexin neurons. This latter finding suggests that, during sleep, orexin neurons are under an endogenous GABAergic inhibition that prevents them from firing (Alam et al., 2005). The source of this synaptic GABA remains unknown, although local GABAergic sleep-active neurons may contribute to the inhibition of orexin neurons during NREM and REM sleep. In support of this hypothesis, single-unit recordings, and cFos studies have shown that the lateral hypothalamus perifornical region (LH/PF) region contains a large number of GABAergic (positive for Vgat immunoreactivity) sleep-active (NREM and REM) neurons (Alam et al., 2002; Koyama et al., 2003; Hassani et al., 2010). While many of these GABAergic sleep-active neurons send descending projections to the brainstem (Verret et al., 2006; Clément et al., 2012), they also provide local collaterals (Hassani et al., 2010) that could inhibit surrounding wake-active neurons during NREM and REM sleep, including the orexin neurons.

Here, we examined local LH/PF GABAergic afferent input to orexin neurons $\left(\mathrm{LH} / \mathrm{PF}^{\mathrm{Vgat}} \rightarrow \mathrm{Orx}\right)$ and, moreover, sought to understand how the $\mathrm{LH} / \mathrm{PF}^{\mathrm{Vgat}} \rightarrow$ Orx circuit may be modulated by cholinergic input and/or local release of orexin and dynorphin. To do so, we expressed channelrhodopsin-2 (ChR2) in LH/ $\mathrm{PF}^{\mathrm{Vgat}}$ neurons, recorded photo-evoked IPSCs in surrounding orexin neurons and examined the effect of bath application of carbachol, orexin, and dynorphin on the photo-evoked IPSCs.

\section{Materials and Methods}

Animals and stereotaxic viral injections. All mice were treated in accordance with guidelines from the National Institutes of Health Guide for the care and use of laboratory animals. All protocols were approved by Beth Israel Deaconess Medical Center Institutional Animal Care and Use Committee. We used 2- to 4-month-old Vgat-IRES-Cre mice of either sex. The Vgat-IRES-Cre mice express cre-recombinase under control of the GABA vesicular transporter promoter to limit recombination to GABAergic neurons (Vong et al., 2011). To activate input from local GABAergic neurons onto orexin neurons, we used in vitro ChR2-assisted circuit mapping with dual adeno-associated virus (AAV) injections. To express ChR2 selectively in LH/PF GABAergic neurons, we, as previously described (Mochizuki et al., 2011), placed unilateral microinjections of AAV-DIO-ChR2-YFP (9-15 nl; anteroposterior: $-1.3 \mathrm{~mm}$, dorsoventral: $-5.2 \mathrm{~mm}$, mediolateral: $0.9 \mathrm{~mm}$ ) (Paxinos and Franklin, 2001) into the LH/PF region of Vgat-IRES-Cre mice ( $n=31$ for whole-cell recordings and $n=2$ for in situ hybridization for Vgat mRNA). This is a cre-dependent AAV coding for ChR2 fused to enhanced yellow fluorescent protein (AAV5 Ef1a-DIO-hChR2 (H134R)-eYFP; $6.6 \times 10^{12}$ virus molecules/ml; prepared by the University of North Carolina Gene Therapy Center, Chapel Hill, NC). To identify orexin neurons in recording slices, we also placed unilateral microinjections of AAV-h-orexintdTomato (120 nl; anteroposterior: $-1.3 \mathrm{~mm}$, dorsoventral: $-5.4 \mathrm{~mm}$, mediolateral: $0.9 \mathrm{~mm}$ ) (Paxinos and Franklin, 2001) into the LH/PF region. In this $\mathrm{AAV}$, the construct contains a $1.3 \mathrm{~kb}$ fragment of the human prepro-orexin promoter that drives expression of tdTomato in orexin neurons (AAV8-h-orexin-tdTomato; $1.7 \times 10^{13} \mathrm{pfu} / \mathrm{ml}$ ). The construct was a kind gift of Takeshi Sakurai, Kanazawa University (Saito et al., 2013), and it was packaged into an AAV8 by University of North Carolina Gene Therapy Center.

Brain slice preparation and recordings. We recorded orexin neurons from across the medial-lateral extent of the orexin field. Orexin neurons were identified by the expression of tdTomato and by post hoc orexin immunoreactivity. We and others have previously shown that $\sim 80 \%$ of the tdTomato-labeled neurons are double-labeled for orexin immunoreactivity (Saito et al., 2013; Agostinelli et al., 2017). The tdTomatolabeled neurons lacking orexin are small $(<10 \mu \mathrm{m})$ and ventral and dorsal to the orexin field whereas all the tdTomato-labeled neurons in the orexin field that were $>20 \mu \mathrm{m}$ express orexin and have the typical physiological characteristics of orexin neurons (Agostinelli et al., 2017). Therefore, we recorded only large $(>20 \mu \mathrm{m})$ tdTomato-labeled neurons in the $\mathrm{LH} / \mathrm{PF}$ region.

Six to 8 weeks after AAV injections, we prepared LH/PF slices for electrophysiological recordings. Mice were anesthetized with isoflurane via inhalation, and we transcardially perfused them with ice-cold cutting $\operatorname{ACSF}(N$-methyl-D-glucamine-based solution) containing (in mM as follows): $100 \mathrm{~N}$-methyl-D-glucamine, $2.5 \mathrm{KCl}, 1.24 \mathrm{NaH}_{2} \mathrm{PO}_{4}, 30 \mathrm{NaHCO}_{3}$, 25 glucose, 20 HEPES, 2 thiourea, $5 \mathrm{Na}$-L-ascorbate, 3 Na-pyruvate, 0.5 $\mathrm{CaCl}_{2}, 10 \mathrm{MgSO}_{4}\left(\mathrm{pH} 7.3\right.$ with $\mathrm{HCl}$ when carbogenated with $95 \% \mathrm{O}_{2}$ and $5 \% \mathrm{CO}_{2}$ ). We quickly removed the mouse brains and sectioned the brains in coronal slices ( $250 \mu \mathrm{m}$ thick) in ice-cold cutting ACSF using a vibrating microtome (VT1200S, Leica Microsystems). We transferred the slices containing the LH/PF to normal ACSF containing (in $\mathrm{mm}$ as follows: $120 \mathrm{NaCl}, 2.5 \mathrm{KCl}, 1.3 \mathrm{MgCl}_{2}, 10$ glucose, $26 \mathrm{NaHCO}_{3}, 1.24$ $\mathrm{NaH}_{2} \mathrm{PO}_{4}, 4 \mathrm{CaCl}_{2}, 2$ thiourea, $1 \mathrm{Na}$-L-ascorbate, 3 Na-pyruvate, $\mathrm{pH} 7.4$ when carbogenated with $95 \% \mathrm{O}_{2}$ and $5 \% \mathrm{CO}_{2}, 310-320 \mathrm{mOsm}$ ).

We recorded from orexin neurons that expressed tdTomato using a combination of fluorescence and infrared differential interference contrast video microscopy. We used a fixed stage upright microscope (BX51WI, Olympus America) equipped with a Nomarski waterimmersion lens (Olympus $40 \times / 0.8 \mathrm{NA} \mathrm{W}$ ) and infrared-sensitive CCD camera (ORCA-ER, Hamamatsu), and we used Micro-Manager software (Open Imaging) to acquire real time images. We recorded in whole-cell configuration using a Multiclamp 700B amplifier (Molecular Devices), a Digidata 1322A interface, and Clampex 9.0 software (Molecular Devices). We photostimulated $\mathrm{LH} / \mathrm{PF}^{\text {Vgat }}$ cell bodies axons and synaptic terminals expressing ChR2 using full-field $10 \mathrm{~ms}$ flashes of light $\left(\sim 10 \mathrm{~mW} / \mathrm{mm}^{2}, 1 \mathrm{~mm}\right.$ beam width, otherwise specified; we photostimulated at $0.1 \mathrm{~Hz}$, for a minimum of 30 trials) from a $5 \mathrm{~W}$ LUXEON blue light-emitting diode (470 nm wavelength; \#M470L2-C4; Thorlabs) coupled to the epifluorescence pathway of the microscope.

For all the recordings in voltage-clamp mode, we used a Cs-methanesulfonate-based pipette solution containing the following (in mM): 125 Cs-methane-sulfonate, $11 \mathrm{KCl}, 10 \mathrm{HEPES}, 0.1 \mathrm{CaCl}_{2}, 1 \mathrm{EGTA}, 5 \mathrm{Mg}$ ATP, and $0.3 \mathrm{Na}-\mathrm{GTP}$ (pH adjusted to 7.2 with $\mathrm{CsOH}, 280 \mathrm{mOsm}$ ). We added $0.5 \%$ biocytin in the pipette solution to mark the recorded neurons. We recorded photo-evoked IPSCs at a holding potential of $0 \mathrm{mV}$ $\left(\mathrm{Cl}^{-}\right.$reversal potential $\left.=-64 \mathrm{mV}\right)$ in ACSF containing $1 \mathrm{~mm}$ kynurenic acid. For the recordings in current-clamp mode, we used a K-gluconatebased pipette solution containing the following (in mM): $120 \mathrm{~K}$-gluconate, 10 $\mathrm{KCl}, 3 \mathrm{MgCl}_{2}, 10$ HEPES, 2.5 K-ATP, 0.5 Na-GTP (pH 7.2 adjusted with $\mathrm{KOH} ; 280$ mOsm).

Data analysis and statistics. We analyzed data using Clampfit 10 (Molecular Devices) and IGOR Pro 6 (WaveMetrics). To ensure unbiased detection of the synaptic events, the IPSCs were detected and analyzed automatically using Mini Analysis 6 software (Synaptosoft). We considered cells to be responsive to photostimulation if their IPSC probability during the first $50 \mathrm{~ms}$ following the light pulses was $>30 \%$ (baseline IPSC probability $=6.28 \pm 0.67 \%, n=116$ ). We considered IPSCs to be photo-evoked if they had a latency within $\pm 1 \mathrm{~ms}$ of the median value calculated in each neuron from the IPSCs recorded in the first $50 \mathrm{~ms}$ following photostimulation. IPSCs with a latency outside that interval 
were considered to be independent of photostimulation. We calculated the latency of the photo-evoked IPSCs as the time difference between the start of the light pulse and the 5\% rise point of the first IPSC (Hull et al., 2009). For the paired pulse test, we used $300 \mathrm{~ms}$ interpulse intervals. To record photo-evoked synaptic events in the presence of TTX $(1 \mu \mathrm{M})$, we bath applied the potassium blocker, 4-AP (1 mM) (Hull et al., 2009; Petreanu et al., 2009). The application of 4-AP prolongs depolarization of the presynaptic terminals and this ensures enough $\mathrm{Ca}^{2+}$ influx to trigger synaptic release in the absence of action potentials (Kole et al., 2007; Shu et al., 2007).

We bath-applied carbachol, orexin, and dynorphin-A (DynA) for 10 min. Unless specified, we calculated the amplitude of photo-evoked IPSC in control ACSF, scopolamine, and nor-BNI by averaging the last 30 photo-evoked IPSCs before the drug applications. We calculated the amplitude of photo-evoked IPSCs for drug applications (carbachol, orexin, and DynA) by averaging the last 30 photo-evoked IPSCs of the 10 min application interval. And, for washout, we calculated amplitude by averaging the last 30 photo-evoked IPSCs of the $20 \mathrm{~min}$ washout interval.

We measured the spontaneous IPSC (sIPSC) frequency over a 5 min interval in control, just before the drug applications (carbachol, orexin or DynA), over the last $5 \mathrm{~min}$ of $10 \mathrm{~min}$ drug applications, and over the last 5 min of 15 min washouts. We statistically compared mean sIPSC interevent interval cumulative distributions using two-way repeatedmeasures ANOVA followed with Bonferroni's multiple-comparisons post hoc test.

We represented data as mean \pm SEM and $n=$ number of cells per group. We compared group means using unpaired, paired $t$ tests, or repeated-measures one-way ANOVA followed by Fisher's LSD post hoc test. An $\alpha<0.05$ was considered significant.

Peak-scaled nonstationary fluctuation analysis. We used peak-scaled nonstationary fluctuation analysis to determine changes in $\mathrm{GABA}_{\mathrm{A}}$ single-channel current $(i)$ or in the number of $\mathrm{GABA}_{\mathrm{A}}$ channels activated $(N)$ in response to carbachol and dynorphin (Robinson et al., 1991; Traynelis et al., 1993; Momiyama et al., 2003). We low-pass filtered and then aligned the peaks of photo-evoked IPSCs. We scaled the averaged mean-current waveform to the peak amplitude of individual photoevoked IPSCs, squared the difference, and then sampled this variance time series in 30 bins of equal current decrement from peak to baseline. The binned variance was plotted against the mean-current amplitude. We estimated the $N$ and the $i$ values by least-squares fitting of the peakscaled variance and mean-current curve to the equation: $\delta^{2}=i I-I^{2} / N$ $+b$, where $\delta^{2}$ is the variance, $I$ is the mean-current, and $b$ is baseline variance. For each cell and each condition (carbachol or dynorphin applications), we selected a minimum of 20 photo-evoked IPSCs that had no overlapping spontaneous IPSCs. All the analysis was done using software written in Python 3 (www.python.org).

Chemicals. We purchased orexin-A from Bachem, DynA, bicuculline methiodide, nor-BNI, and carbachol from Tocris Bioscience, scopolamine from Abcam, and TTX and kynurenic acid from Cayman Chemical. All other chemicals were from Fisher Scientific.

Immunohistochemistry. Immediately following the in vitro recordings, recorded and adjacent slices were fixed overnight in 10\% buffered formalin. To verify the location of ChR2-YFP-expressing neurons, we immunolabeled all the slices against YFP. We incubated them over two nights in chicken anti-GFP antibody (1:500; Invitrogen). This is a polyclonal antibody that reliably detects GFP as well as YFP. We then incubated the slices overnight in Alexa-488-conjugated donkey anti-chicken antibodies (1:500; Jackson ImmunoResearch Laboratories). We wet mounted the immunolabeled slices, and we scanned whole sections using a slide scanner (Olympus VS120) at a final magnification of $200 \times$. We used a $z$-stack at $1 \mu \mathrm{m}$ intervals to image through the section. We viewed stacks of images using OlyVIA software to identify the region containing transduced somata. We plotted the outline regions containing ChR2YFP neurons onto template drawings (Paxinos and Franklin, 2001) using Photoshop (Adobe). We compiled the distribution of ChR2-YFP expression in a color map using a Python script (www.python.org) generously provided by Dr. Venner (Harvard University) (Venner et al., 2016). We represented the region of overlap of the maximum number of overlapping cases in white, with the hues to yellow, orange, to deep red indicating fewer cases.

After completing the mapping of the ChR2-YFP-expressing neurons, we further processed the recorded slices for orexin immunolabeling. We incubated the recorded slices over two nights in goat anti-orexin-A primary antibody (1:500; Santa Cruz Biotechnology), followed by an overnight incubation in mouse Alexa-647-conjugated anti-goat secondary antibodies (1:500; Jackson ImmunoResearch Laboratories) and streptavidin-conjugated Alexa-405 (1:500; Invitrogen) to label the recorded neurons filled with biocytin. We used confocal microscopy to verify that the recorded neurons (labeled in blue- Alexa-405) were double-labeled for orexin immunoreactivity (labeled in far-red-Alexa647). We imaged and photographed double-labeled sections using a LSM 880 confocal microscope (Carl Zeiss). We pseudocolored far-red as magenta.

For the immunostaining in Figure $1 B$, we incubated the sections (40 $\mu \mathrm{m})$ overnight in chicken anti-GFP antibody (1:5000; Invitrogen), followed by $2 \mathrm{~h}$ incubation in donkey biotin-conjugated anti-chicken secondary antibodies (1:500, Jackson ImmunoResearch Laboratories) and then $1 \mathrm{~h}$ incubation in streptavidin-conjugated Cy5 (1:1000, Invitrogen). We imaged and photographed the sections using a Zeiss LSM 880 confocal microscope. We pseudocolored Cy5 as green.

We performed digoxigenin-labeled RNA probe in situ hybridization for Vgat RNA in two Vgat-IRES-Cre mice injected with AAV-DIO-ChR2YFP into the LH/PF region. Eight weeks after AAV injection, we anesthetized the mice with isoflurane via inhalation and transcardially perfused them with $50 \mathrm{ml}$ of buffered 10\% formalin ( $\mathrm{pH}$ 7.0; Fisher Scientific). Brains were then postfixed in formalin overnight, cryoprotected in a $20 \%$ sucrose solution, and cut into $40 \mu \mathrm{m}$ sections. Sections were washed in RNase-free phosphate-buffered saline (PBS), containing diethylpyrocarbonate and then incubated in hybridization buffer at $53^{\circ} \mathrm{C}(1 \mathrm{~h})$. The Vgat probe was denatured at $80^{\circ} \mathrm{C}(10 \mathrm{~min})$, and then it was added to the hybridization buffer and incubated overnight at $53^{\circ} \mathrm{C}$. The sections were then washed in saline citrate with $50 \%$ formamide at $53^{\circ} \mathrm{C}(2 \mathrm{~h})$. Sections were washed in Tris buffered saline (TBS) ( $\mathrm{pH} 7.5 ; 30 \mathrm{~min})$, incubated in $1 \%$ blocking reagent (Roche Applied Science; $30 \mathrm{~min}$ ) and then incubated overnight in peroxidase conjugated digoxigenin antibody (1:500, Roche Applied Science). After being washed in TBS, the sections underwent Tyramide signal amplification Cy3 (1:50, PerkinElmer; 30 min); then they were washed first in TBS and then in PBS, mounted and coverslipped in deionized water. The Vgat probes were produced by Dr. Shigefumi Yokota (University School of Medicine, Izumo, Japan). We imaged and photographed the sections using a Zeiss LSM 880 confocal microscope.

\section{Results}

To test whether the activity of orexin neurons is controlled by local GABAergic neurons, we used ChR2-assisted circuit mapping in vitro brain slices. We specifically expressed ChR2 in GABAergic neurons in the LH/PF region and recorded from fluorescently labeled orexin neurons. To do so, we injected a cre-dependent $A A V$-DIO-ChR2-YFP and an AAV-h-orexintdTomato into the LH/PF region of Vgat-IRES-Cre mice (Vong et al., 2011). These injections produce expression of ChR2-YFP in GABAergic neurons and tdTomato in orexin neurons (Fig. $1 A, B)$. Histological assessment confirmed expression of ChR2 restricted to neurons in the $\mathrm{LH} / \mathrm{PF}$ region. Transduced neurons from individual injections spanned, in the rostral caudal dimension, from the retrochiasmatic hypothalamus to the caudal pole of the dorsomedial hypothalamus, with the shared region of transduction ( $>80 \%$ of mice) spanning from the rostral ventromedial hypothalamus to the compacta region of the dorsomedial hypothalamic nucleus. Within this rostral-caudal continuum, transduced neurons were predominately located lateral to the fornix, medial to the optic tract and ventral to the zona incerta (see transduction map, Fig. 1C). 
A

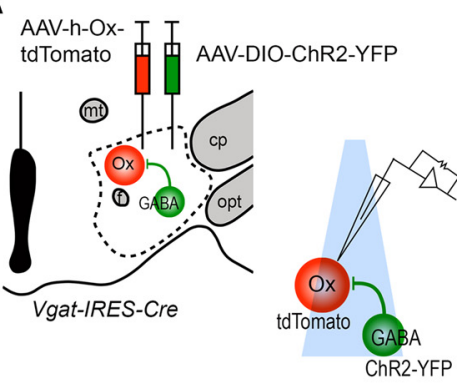

D

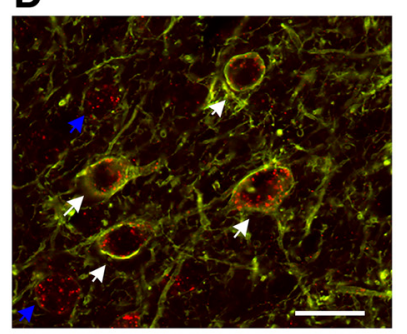

$\mathbf{E}$
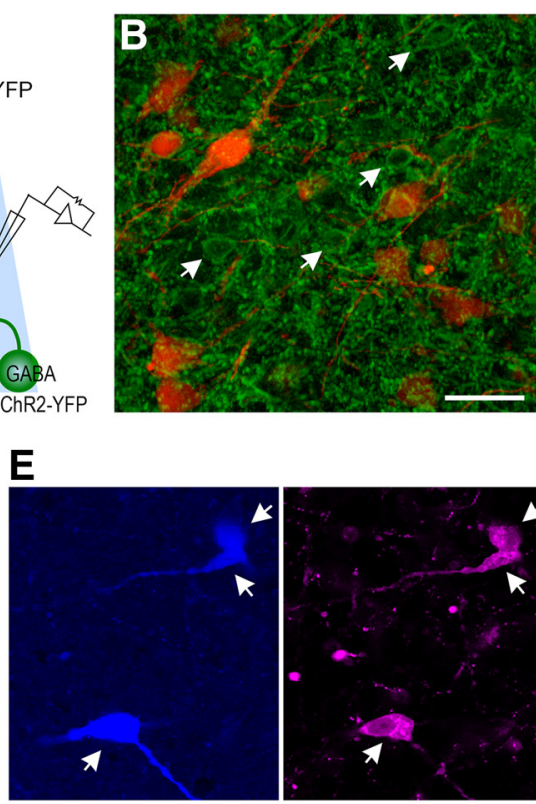
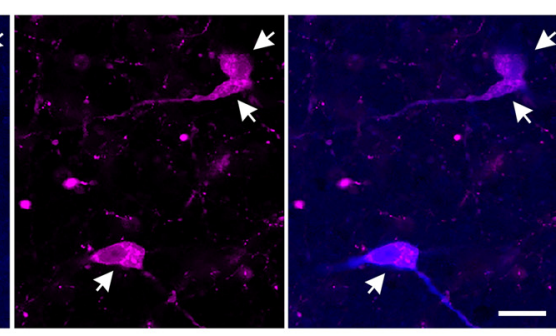
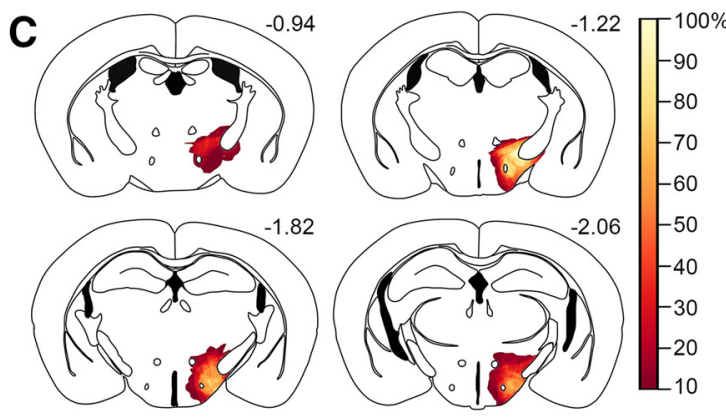

$\mathbf{F}$

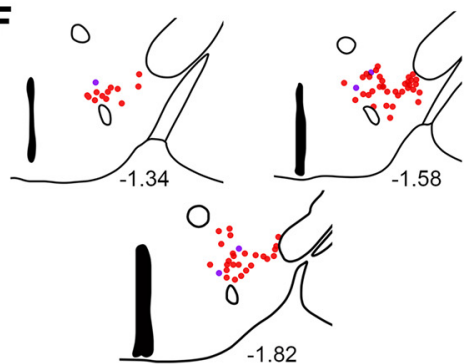

Figure 1. ChR2 circuit-assisted mapping of LH/PF ${ }^{V \text { gat }} \rightarrow$ Orx input. $A$, Schematic of the experimental design used to map connectivity between local GABAergic neurons and orexin neurons in brain slices (LH/PF Vgat $\rightarrow$ Orx). We injected an AAV-DIO-ChR2-YFP and an AAV-h-orexin-tdTomato into the LH/PF region of Vgat-IRES-Cre mice to produce expression of ChR2-YFP in GABAergic neurons and tdTomato in orexin neurons. Six weeks after the AAV injections, we recorded in brain slices. We photostimulated cell bodies and terminals of local GABAergic neurons while recording from orexin neurons that express tdTomato. B, An example of a Vgat-IRES-Cre mouse injected with AAV-DIO-ChR2-YFP and AAV-h-orexin-tdTomato. Confocal photomicrograph showing, in the perifornical region, local GABAergic neurons expressing ChR2-YFP (green represents immunolabeled against YFP; indicated by arrows) and native tdTomato fluorescence in orexin neurons (red). Scale bars, $40 \mu \mathrm{m}$. C, Heatmap of AAV-DIO-ChR2-YFP injection sites of 29 recorded Vgat-IRES-Cre mice showing overlapping regions of ChR2-YFP-expressing neurons. D, Confocal images of ChR2-YFP-expressing neurons (in green) and in situ hybridization for Vgat RNA (red). Scale bar, $20 \mu \mathrm{m}$. White arrows indicate double-labeled neurons. Blue arrows indicate individual neurons expressing Vgat mRNA but not ChR2-YFP. E, Confocal images of 3 recorded tdTomato-expressing neurons filled with biocytin and post hoc labeled with streptavidin-conjugated Alexa-405 (in blue) that are double-labeled for orexin immunoreactivity (magenta). Scale bar, $40 \mu \mathrm{m} . \boldsymbol{F}$, Map of the distribution of $n=77$ recorded neurons that were found after post hoc labeling for biocytin. Red dots indicate 72 recorded neurons $(+)$ for orexin immunoreactivity. Blue dots indicate 5 recorded neurons ( - ) for orexin immunoreactivity. Atlas levels are per Paxinos and Franklin (2001). opt, Optic tract; $c p$, cerebral peduncle; $m t$, mammillothalamic tract; $f$, fornix.

To test the selectivity of the AAV-DIO-ChR2-YFP for Vgat expressing neurons in the LH/PF region, we performed digoxigenin-labeled RNA probe in situ hybridization for Vgat RNA in two Vgat-IRES-Cre mice injected with AAV-DIO-ChR2YFP into the LH/PF region. We found a high level of selectivity: 98.9\% of neurons expressing ChR2-YFP $(n=266)$ also expressed Vgat mRNA (Fig. 1D). Some neurons (30.5\%) expressed Vgat but not ChR2-YFP.

The AAV-h-orexin-tdTomato efficiently labels orexin neurons so that they can be visualized for in vitro electrophysiological recordings (Saito et al., 2013; Agostinelli et al., 2017). We recorded from 121 tdTomato-labeled neurons in the perifornical region. We efficiently labeled 80 of the 121 recorded neurons with biocytin from the recording pipette and processed the recorded slices for orexin immonoreactivity. Seventy-five of 80 biocytinfilled neurons were immunolabeled for orexin, confirming the orexin phenotype of the recorded neurons (Fig. 1E,F). The recorded neurons that were negative for orexin immunoreactivity were discarded. Of the 116 tdTomato-labeled neurons used in the analysis, 75 were further confirmed to be orexincontaining neurons by immunostaining for orexin and 41 were only identified by the expression of tdTomato. Based on the results from the 80 biocytin-labeled neurons, we estimated that following the injection of AAV-h-orexin-tdTomato, $\sim 6 \%$ ( 5 of 80 ) of the tdTomato-labeled neurons might not express orexin.

Photostimulation of the GABAergic neurons in the LH/PF region inhibited the firing of orexin neurons (Fig. 2A) and evoked IPSCs in 71 of 116 recorded orexin neurons (Fig. $2 B-D$ ). In addition, of the recorded neurons in which the orexin phenotype was determined by both expression of tdTomato and post hoc immunoreactivity for orexin, 53 of 75 responded to photoactivation of the $\mathrm{LH} / \mathrm{PF}^{\mathrm{Vgat}} \rightarrow$ Orx input. Photo-evoked IPSCs were blocked by bicuculline $(n=3)$, indicating release of GABA and activation of $\mathrm{GABA}_{\mathrm{A}}$ receptors (Fig. $2 B$ ). Neurons that responded to photostimulation $(n=71)$ had photo-evoked IPSCs in response to two-thirds of the light pulses (average probability: $77.3 \pm 2.7 \%$; Fig. $2 D$ ). There was no difference in baseline sIPSC probability between neurons that responded to photostimulation $(n=71)$ and neurons that did not $(n=45$; two-way ANOVA, $F=0.86, p=0.56$; Fig. $2 D$ ).

Photostimulation of the LH/PF ${ }^{\text {Vgat }} \rightarrow$ Orx input evoked IPSCs in orexin neurons also in the absence of action potentials. As others have reported in ChR2-assisted circuit mapping studies (Hull et al., 2009; Dergacheva et al., 2017), we also found that TTX $(1 \mu \mathrm{M})$ alone eliminates the photo-evoked IPSCs, but they

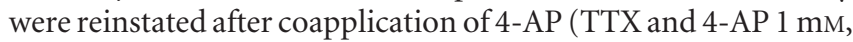
in 12 of 14 neurons tested). These results support direct monosynaptic connectivity between LH/PF GABAergic neurons and most of the orexin neurons (Fig. 2E). In two of these neurons in which the photo-evoked IPSCs were maintained in TTX and 4-AP, the orexin phenotype was determined by both the expression of tdTomato and by post hoc immunoreactivity for orexin. Paired pulse tests (300 ms interpulse intervals) showed robust paired pulse depression $(0.386 \pm 0.086, n=8 ; p=0.013$, paired $t$ test, comparing $\mathrm{P} 1$ vs $\mathrm{P} 2$ photo-evoked IPSC amplitudes), suggesting high synaptic release probability in response to photostimulation of LH/PF ${ }^{\text {Vgat }} \rightarrow$ Orx input (Fig. $2 F$ ). The average photo-evoked IPSC peak amplitude was $46.73 \pm 5.54 \mathrm{pA}$, and photo-evoked IPSC latency was $7.23 \pm 0.35 \mathrm{~ms}(n=71$; Fig. 
$2 G, H)$. Furthermore, the neurons in which connectivity was maintained in TTX had an average photo-evoked IPSC latency of $6.27 \pm 0.54 \mathrm{~ms}(n=12)$, whereas the two neurons in which the photo-evoked IPSCs disappeared in TTX had longer latencies: $14.1 \mathrm{~ms}$ and $17.9 \mathrm{~ms}$ (Fig. 2G,H). Long latency together with TTX sensitivity in a small number of neurons is supportive of additional polysynaptic connectivity.

\section{The effects of carbachol, orexin, and dynorphin on the $\mathrm{LH} / \mathrm{PF}^{\text {Vgat }} \rightarrow$ Orx input}

The orexin field is innervated by cholinergic fibers (Schäfer et al., 1998), and cholinergic agonists depolarize and increase the firing of orexin neurons through the activation of postsynaptic muscarinic receptors (Yamanaka et al., 2003; Bayer et al., 2005; Ohno et al., 2008). We therefore examined the effects of carbachol specifically on input from local GABAergic neurons to orexin neurons $\left(\mathrm{LH} / \mathrm{PF}^{\mathrm{Vgat}} \rightarrow \mathrm{Orx}\right)$. We photostimulated LH/PF GABAergic neurons and tested the effects of carbachol on photo-evoked IPSCs in orexin neurons (Fig. 3). Carbachol $(15 \mu \mathrm{M})$ reduced the amplitude of the photo-evoked IPSCs by $47.91 \pm 6.97 \%$, and this effect was reversed after $20 \mathrm{~min}$ washout $(n=10$; repeatedmeasures one-way ANOVA and Fisher's LSD post hoc test, $p=0.021$, control vs carbachol and $p=0.024$, washout vs carbachol; Fig. 3A). Of these 10 neurons in which carbachol inhibited the $\mathrm{LH} / \mathrm{PF}^{\text {Vgat }} \rightarrow$ Orx input, 8 were identified as orexin containing neurons by both the expression of $\mathrm{td}$ Tomato and by post hoc immunoreactivity for orexin. The muscarinic receptor antagonist scopolamine $(10 \mu \mathrm{M})$ abolished the effect of carbachol $(n=5 ; p=0.85$, paired $t$ test when comparing the photoevoked IPSC amplitude in scopolamine vs scopolamine + carbachol and $p<0.001$ unpaired $t$ test when comparing the reduction of the photo-evoked IPSC amplitude by carbachol in control ACSF and by carbachol in scopolamine), demonstrating that carbachol inhibits the LH/ $\mathrm{PF}^{\text {Vgat }} \rightarrow$ Orx input through muscarinic receptors (Fig. $3 B, C$ ). The effect of carbachol on the photo-evoked IPSC amplitude was not associated with changes in photo-evoked latency $(n=10$; one-way ANOVA, $F=0.182, p=$ 0.834 ; Fig. $3 D$ ) or probability (one-way ANOVA, $F=2.453, p=$ 0.105 ; Fig. $3 E$ ). We also found that in the same neurons in which carbachol inhibited the LH/PF ${ }^{\text {Vgat }} \rightarrow$ Orx input, carbachol had no effect on the sIPSC frequency $(n=10$, one-way ANOVA, $F=$ $0.038, p=0.963$; Fig. $3 F, G$ ). This finding indicates that, while the $\mathrm{LH} / \mathrm{PF}^{\text {Vgat }} \rightarrow$ Orx input is greatly suppressed by cholinergic agonists, most of the GABAergic input to the orexin neurons is un-
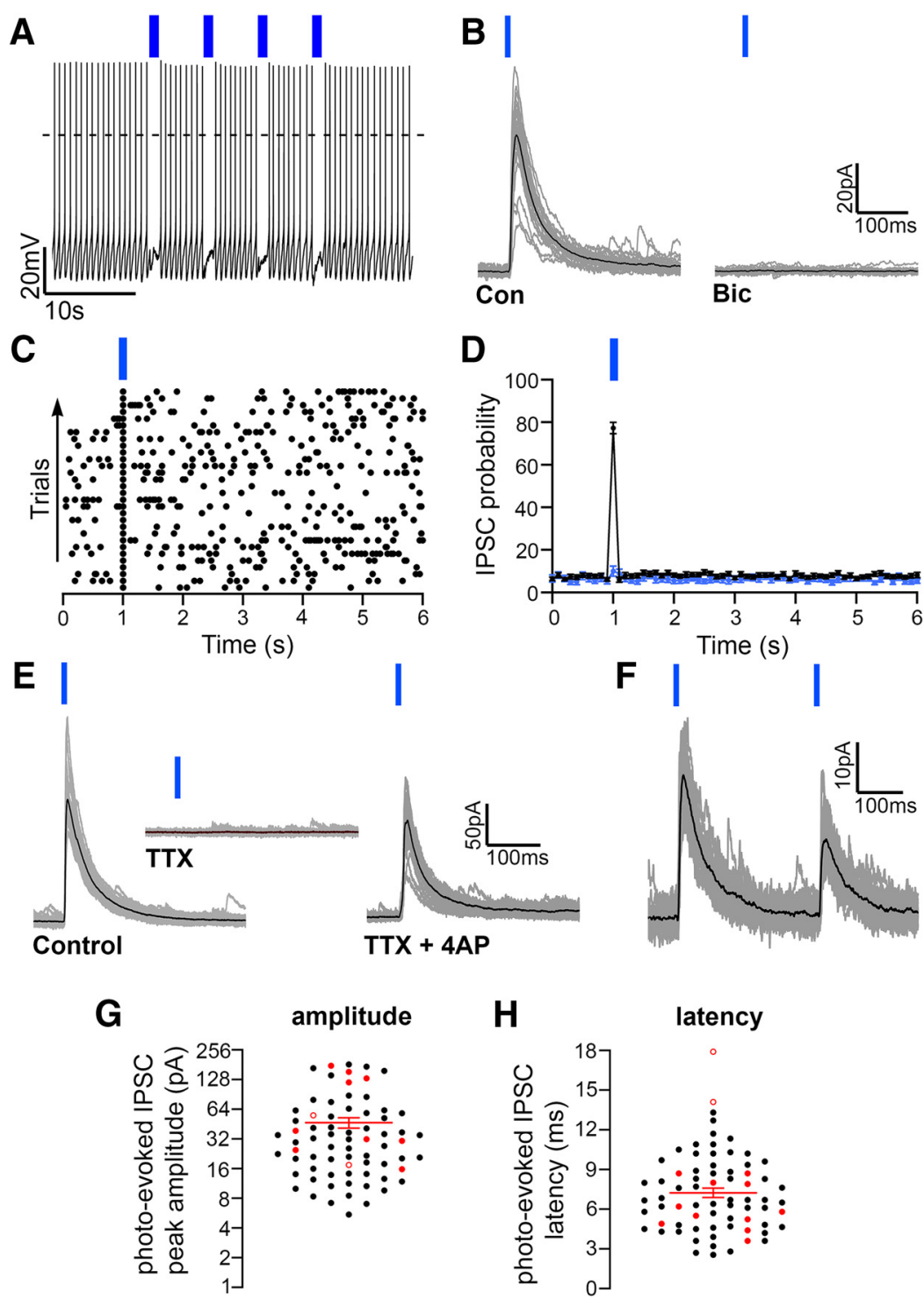

latency

Figure 2. Orexin neurons are inhibited by local GABAergic neurons (LH/PF Vgat $\rightarrow$ Orx input). $A$, Photostimulation of LH/PF ${ }^{\text {Vgat }}$ neurons and terminals expressing ChR2 inhibits action potential firing of orexin neurons (4 trains at $10 \mathrm{~Hz}$; K-gluconate-based pipette solution). $\boldsymbol{B}$, In voltage-clamp mode, photostimulation of the LH/PF ${ }^{\text {gat }} \rightarrow 0$ rx input evokes photo-evoked IPSCs in orexin neurons that are blocked by bicuculline $(20 \mu \mathrm{m})$ demonstrating release of GABA. Gray represents 30 photo-evoked IPSCs. Black represents average photo-evoked IPSCS. C, Raster plot of GABAergic IPSCs in a representative orexin neuron before, during, and after stimulation of LH/PF Vgat $\rightarrow$ Orx pathway $(50 \mathrm{~ms}$ bins). D, Average IPSC probability of neurons that responded to the activation of the $\mathrm{LH} / \mathrm{PF}{ }^{\mathrm{Vgat}} \rightarrow$ Orx input ( $n=71$ neurons; black dots) and of neurons that did not respond to photostimulation ( $n=45$; blue dots; $100 \mathrm{~ms}$ bins). E, Photo-evoked IPSCs recorded in control ACSF (left) are blocked in TTX (1 $\mu \mathrm{m}$; middle) and are reinstated when TTX is coapplied with 4-AP (right; TTX $1 \mu \mathrm{M}+4-\mathrm{AP} 1 \mathrm{mM}$ ) indicating monosynaptic connectivity. Gray represents 30 photo-evoked IPSCS. Black represents average photo-evoked IPSC. $\boldsymbol{F}$, Pairs of photo-evoked IPSCS (300 ms intervals) show robust paired pulse depression. $\boldsymbol{G}, \boldsymbol{H}$, Photo-evoked IPSC amplitude $(\boldsymbol{G})$ and latency $(\boldsymbol{H})$. Black dots indicate mean values of individual orexin neurons. Red filled dots indicate mean values of neurons in which connectivity was then tested in TTX and was TTX-resistant. Red empty dots indicate mean values of neurons in which connectivity was blocked by TTX (for each cell, the average of the photo-evoked IPSCS was calculated from the response to 30 trials). Red lines indicate population mean \pm SEM $(n=71)$. Photo-evoked IPSCs were evoked by single (in $\boldsymbol{B}-\boldsymbol{E}$ ), pairs (in $\boldsymbol{F}$ ) or trains (in $\boldsymbol{A}$ ) of $10 \mathrm{~ms}$ light pulses and were recorded at $V_{\mathrm{h}}=0$ $\mathrm{mV}$ using the Cs-methane-sulfonate-based pipette solution.

affected, suggesting that the cholinergic control of the GABAergic input to orexin neurons is input selective.

During wakefulness, orexin is released locally and acts in a positive feedback manner on orexin neurons (Kiyashchenko et al., 2002; Li et al., 2002; Yamanaka et al., 2010). We therefore examined the effects of orexin on the $\mathrm{LH} / \mathrm{PF}^{\mathrm{Vgat}} \rightarrow$ Orx input and found that orexin-A ( $300 \mathrm{~nm}$ ) had no effects on the amplitude of the photo-evoked IPSCs $(n=7 ; p=0.24$, paired $t$ test; when 


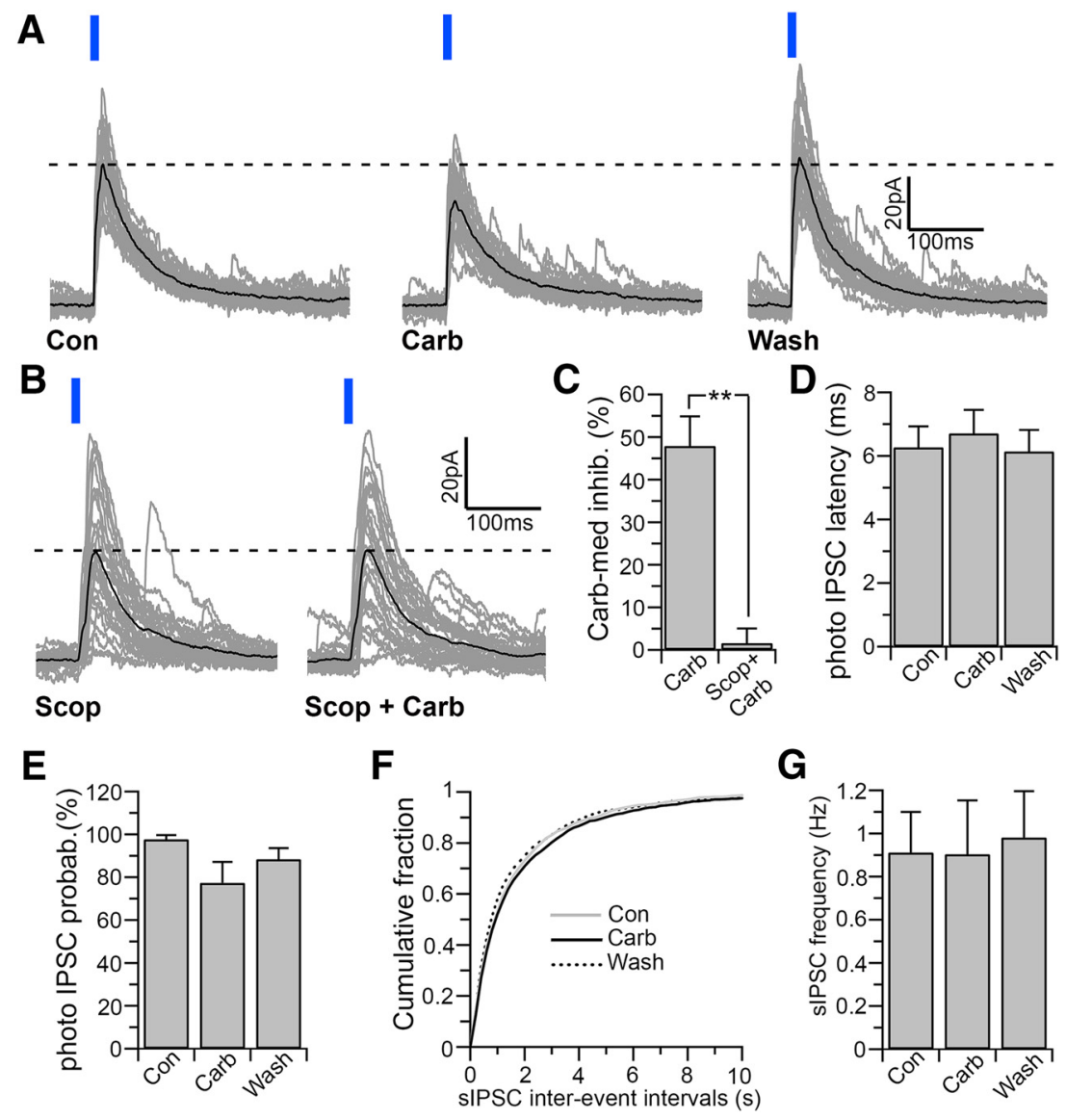

Figure 3. Carbachol inhibits LH/PF ${ }^{\mathrm{Vgat}} \rightarrow$ Orxinput. $A, B$, Carbachol ( $\left.15 \mu \mathrm{m}\right)$ reduces the amplitude of the photo-evoked IPSCS, and this effect is blocked by the muscarinic receptor antagonist, scopolamine (10 $\mu \mathrm{m} ; \boldsymbol{B})$. Gray represents 30 photo-evoked IPSCS. Black represents average photo-evoked IPSCS. C, Summary graph comparing the carbachol-mediated inhibition in control ACSF (Carb; $n=10$ ) and in the presence of scopolamine (Scop + Carb; $n=5)$. ${ }^{* *} p<0.01$ (unpaired $t$ test). $\boldsymbol{D}, \boldsymbol{E}$, Carbachol has no significant effect on the photo-evoked IPSC latency ( $\boldsymbol{D} ; n=10$; one-way ANOVA, $F=0.182, p=0.834$ ) or photo-evoked IPSC probability $(\boldsymbol{E} ; n=10$; one-way ANOVA, $F=2.453, p=0.105) . \boldsymbol{F}, \mathbf{G}$, In the same neurons in which carbachol inhibits the $\mathrm{LH} / \mathrm{PF}^{\mathrm{Vgat}} \rightarrow$ Orx input, carbachol has no effect on the sIPSC frequency. Cumulative distribution plots of $s$ IPSC interevent intervals compiled from 10 orexin neurons ( $\boldsymbol{F} ; 200 \mathrm{~ms}$ bins; two-way ANOVA, $F=0.79, p=0.99)$. Mean values of $\operatorname{sIPSC}$ frequency $(\boldsymbol{G} ; n=$ 10 ; one-way ANOVA, $F=0.038, p=0.963)$. Photo-evoked IPSCs were evoked by $10 \mathrm{~ms}$ light pulses and were recorded at $V_{\mathrm{h}}=$ $0 \mathrm{mV}$ using the Cs-methane-sulfonate-based pipette solution.

comparing the photo-evoked IPSC amplitude in control ACSF vs orexin; Fig. $4 A, B$ ), indicating that $\mathrm{LH} / \mathrm{PF}^{\mathrm{Vgat}} \rightarrow$ Orx input is not controlled by local release of orexin. Of these seven neurons in which orexin had no effect on the $\mathrm{LH} / \mathrm{PF}^{\text {Vgat }} \rightarrow$ Orx input, 5 were identified as orexin containing neurons by both the expression of tdTomato and by post hoc immunoreactivity for orexin. We also found that orexin-A did not affect the photoevoked IPSC latency $(n=7$; one-way ANOVA, $F=0.223$, $p=$ 0.803; Fig. $4 C$ ), or probability (one one-way ANOVA, $F=$ 2.882, $p=0.089$; Fig. $4 D$ ) and in the same neurons in which orexin-A had no effect on the $\mathrm{LH} / \mathrm{PF}^{\text {Vgat }} \rightarrow$ Orx input, orexin-A significantly increased the sIPSC frequency $(+27.90 \pm 8.03 \% ; n=7$; one-way ANOVA and Fisher's LSD post hoc test, $p=0.029$, control vs orexin-A; and $p=0.0347$; Fig. $4 E, F)$. Thus, unlike carbachol that only reduced the LH/ $\mathrm{PF}^{\mathrm{Vgat}} \rightarrow$ Orx input but had no effect on the sIPSC frequency, orexin-A had no effect on the input from local GABAergic neurons $\left(\mathrm{LH} / \mathrm{PF}^{\text {Vgat }} \rightarrow\right.$ Orx input), but it increased the frequency of the overall GABAergic input to orexin neurons. The source of this GABAergic input that is increased by orexin remains unknown.
Orexin neurons also produce and corelease the endogenous opiate dynorphin (Chou et al., 2001; Torrealba et al., 2003; Crocker et al., 2005; Muschamp et al., 2014). Dynorphin inhibits orexin neurons directly and indirectly by depressing glutamatergic afferent inputs to orexin neurons (Li and van den Pol, 2006). We next examined the effects of dynorphin on the $\mathrm{LH} / \mathrm{PF}^{\text {Vgat }} \rightarrow$ Orx input. DynA (500 $\mathrm{nM})$ reduced the amplitude of the photoevoked IPSCs by $37.53 \pm 5.99 \%$, and was reversed after $20 \mathrm{~min}$ washout $(n=7$ oneway ANOVA and Fisher's LSD post hoc test, $p=0.047$, control vs DynA and $p=$ 0.048, washout vs DynA; Fig. $5 A$ ). In 4 of these 7 neurons, the orexin phenotype was determined by both the expression of $\mathrm{td}$ Tomato and by post hoc immunoreactivity for orexin). The $\kappa$-opioid receptor antagonist nor-BNI ( $1 \mu \mathrm{M})$ completely abolished the effects of DynA on the photoevoked IPSC amplitude, demonstrating that DynA inhibits the $\mathrm{LH} / \mathrm{PF}^{\mathrm{Vgat}} \rightarrow$ Orx input through the activation of $\kappa$-opioid receptors $(n=5 ; p=0.311$, paired $t$ test when comparing the photo-evoked IPSC amplitude in nor-BNI vs nor-BNI + DynA and $p=0.0015$ unpaired $t$ test when comparing photo-evoked IPSC amplitude by DynA in control ACSF and by DynA in nor-BNI; Fig. 5B,C). In addition, dynorphin directly inhibits orexin neurons, and this effect has been shown to quickly desensitize (Li and van den Pol, 2006). Conversely, we found that the effect of DynA on the LH/PF ${ }^{\text {Vgat }} \rightarrow$ Orx input did not desensitize during the $10 \mathrm{~min}$ application $(n=7, p=0.169$, paired $t$ test when comparing DynA-mediated inhibition of photo-evoked IPSCs at $5 \mathrm{~min}$ vs 10 min DynA applications; Fig. 5A,C). We also found that DynA did not affect the photo-evoked IPSC latency $(n=7$; one-way ANOVA, $F=0.146, p=0.866$; Fig. $5 D)$, or probability (one-way ANOVA, $F=1.084, p=0.359$; Fig. $5 E$ ). In the same neurons in which DynA inhibited the $\mathrm{LH} / \mathrm{PF}^{\mathrm{Vgat}} \rightarrow$ Orx input, DynA also significantly reduced the sIPSC frequency: $29.76 \pm 7.69 \%(n=7$, one-way ANOVA and Fisher's LSD post hoc test, $p=0.019$, control vs DynA; Fig. $5 F, G)$. Unlike carbachol and orexin, DynA reduced both the LH/PF ${ }^{\text {Vgat }} \rightarrow$ Orx input and the overall GABAergic input to orexin neurons.

We next used the peak-scaled nonstationary fluctuation analysis (Traynelis et al., 1993; Momiyama et al., 2003) to assess whether carbachol and dynorphin inhibit the $\mathrm{LH} / \mathrm{PF}^{\text {Vgat }} \rightarrow$ Orx input by affecting the unitary $\mathrm{GABA}_{\mathrm{A}}$ current or the number of $\mathrm{GABA}_{\mathrm{A}}$ receptors activated or both (Fig. 6). For each cell, we obtained parabolic variance versus current amplitude curves. We estimated the ionic channel current (i) and the number of activated channels $(N)$ open at the peak of the photo-evoked IPSCs, in control and during carbachol and DynA inhibition of the photo-evoked IPSCs. We found that carbachol and DynA reduced the photo-evoked IPSC amplitude not by reducing $\mathrm{GABA}_{\mathrm{A}}$ unitary current, which remained unchanged (" $i$ " in control: 
$0.52 x \pm 0.02 \mathrm{pA}$; carbachol: $0.51 \pm 0.04$ $\mathrm{pA} ; n=8, p=0.64$, paired $t$ test; Fig. $6 A, B$; and control: $0.52 \pm 0.03 \mathrm{pA}$; and in DynA: $0.52 \pm 0.03 \mathrm{pA} ; n=8, p=0.34$, paired $t$ test; Fig. $6 C, D)$, but by decreasing the number of activated $\mathrm{GABA}_{\mathrm{A}}$ channels ( $N$ in control: $129.3 \pm 26.4$; carbachol: $81.1 \pm 16.7 ; n=8, p=0.009$, paired $t$ test; DynA: $114.2 \pm 34.3 ; n=8, p=0.004$, paired $t$ test; Fig. $6 C, D$ ). These results indicate that both carbachol and dynorphin likely reduce the amount of GABA released by $\mathrm{LH} / \mathrm{PF}^{\text {Vgat }}$ neurons onto the orexin neurons $\left(\mathrm{LH} / \mathrm{PF}^{\text {Vgat }} \rightarrow\right.$ Orx $)$.

\section{Discussion}

Using ChR2-assisted circuit mapping, we showed that GABAergic neurons in the $\mathrm{LH} / \mathrm{PF}$ region directly inhibit surrounding orexin neurons through the release of GABA and activation of $\mathrm{GABA}_{\mathrm{A}}$ receptors. We then demonstrated that carbachol depresses LH/PF ${ }^{\text {Vgat }} \rightarrow$ Orx input through muscarinic receptors, that orexin has no effect on $\mathrm{LH} / \mathrm{PF}^{\mathrm{Vgat}} \rightarrow$ Orx input, and that dynorphin reduces $\mathrm{LH} / \mathrm{PF}^{\text {Vgat }} \rightarrow$ Orx input strength through $\kappa$-opioid receptor signaling. Fig. $6 A, B$; and control: $160.7 \pm 38.6$;
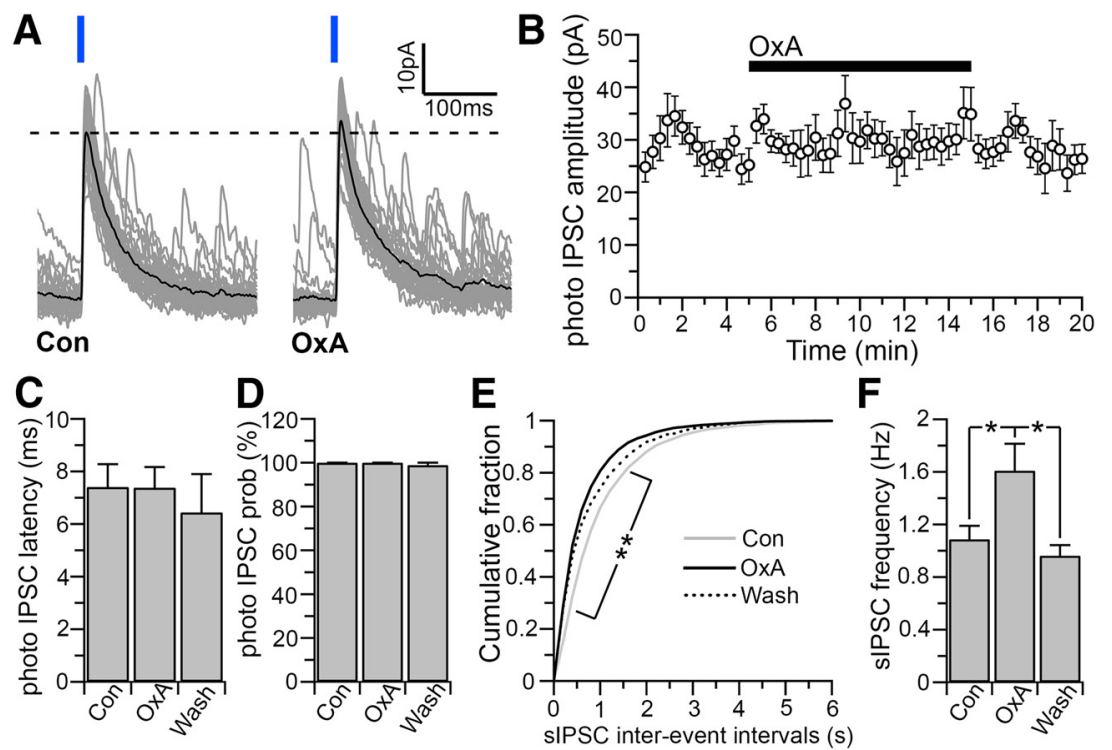

Figure 4. Effects of orexin on the LH/PF Vgat $\rightarrow$ Orx input. $A$, Orexin-A (300 nm) produces no changes on photo-evoked IPSC amplitude. Gray represents 30 photo-evoked IPSCs. Black represents average photo-evoked IPSCs. $\boldsymbol{B}$, Time course of photo-evoked amplitude before, during, and after orexin application (mean photo-evoked IPSC $; n=7$ ). $\boldsymbol{C}, \boldsymbol{D}$, Orexin has no significant effect on photo-evoked IPSC latency $(\boldsymbol{C}, n=7$; one-way ANOVA, $F=0.223, p=0.803)$ or photo-evoked IPSC probability $(\boldsymbol{D}, n=7 ;$ one one-way ANOVA, $F=2.882, p=0.089) . \boldsymbol{E}, \boldsymbol{F}$, In the same neurons in which orexin has no effects on the photo-evoked IPSCS, orexin increases the sIPSC frequency. Cumulative distribution plots of sIPSC interevent intervals compiled from 7 orexin neurons ( $\boldsymbol{E} ; 200$ ms bins; two-way ANOVA, $F=2.276, p<0.001$; Bonferroni's multiple-comparisons post hoc test, ${ }^{*} p<0.05$ comparing control and $0 x A)$. Mean values of sIPSC frequency $\left(\boldsymbol{F} ; n=7\right.$; one-way ANOVA, $F=4.113, p=0.0393 ;{ }^{* *} p<0.01$, Fisher's LSD post hoc test). IPSCs were evoked by $10 \mathrm{~ms}$ light pulses and were recorded at $V_{\mathrm{h}}=0 \mathrm{mV}$ using the $(\mathrm{s}$-methane-sulfonate-based pipette solution.

\section{Local GABAergic input to orexin neurons}

The activity of orexin neurons is controlled by ascending and descending afferent inputs (Yoshida et al., 2006) from many brain regions implicated in behavioral state regulation, including the following: the basal forebrain, preoptic area, posterior hypothalamus, dorsal raphe nucleus, and parabrachial nucleus (Sakurai et al., 2005; Henny and Jones, 2006b; Yoshida et al., 2006; Fuller et al., 2011; Anaclet et al., 2015; González et al., 2016). Recent in vitro optogenetic studies have confirmed functional synaptic connectivity for some, but not all, of these inputs (Muraki et al., 2004; Saito et al., 2013; Chowdhury and Yamanaka, 2016; Agostinelli et al., 2017). In addition, there is evidence that local neurons within the orexin field may contribute to the regulation of orexin neuronal activity, although we are just starting to understand how this local circuitry functions (Burt et al., 2011; Bonnavion et al., 2016).

In the present study, we used ChR2-assisted circuit mapping in brain slices, to selectively activate the $\mathrm{LH} / \mathrm{PF}^{\mathrm{Vgat}} \rightarrow$ Orx input. To identify the orexin neurons, we labeled them using AAV- $h$ orexin-tdTomato injected in the LH/PF region. Consistent with previous studies, we found that $\sim 94 \%$ of the recorded tdTomato-labeled cells were double-labeled for orexin immunoreactivity (Saito et al., 2013; Agostinelli et al., 2017). Optogenetic stimulation of the LH/PF GABAergic neurons confirmed synaptic connectivity to the orexin neurons ( $\mathrm{LH} / \mathrm{PF}^{\text {Vgat }} \rightarrow$ Orx input). We found that photostimulation of GABAergic neurons (i.e., $\mathrm{Vgat}^{+}$) in the LH/PF region inhibited the firing of surrounding orexin neurons through $\mathrm{GABA}_{\mathrm{A}}$ signaling and this input is mainly monosynaptic. In addition, the long response latency ( $>10 \mathrm{~ms})$ of some orexin neurons $(\sim 18 \%)$ and the sensitivity of photo-evoked IPSCs to TTX ( 2 of 14 neurons) suggest the existence of additional polysynaptic connectivity. We also found that $\sim 60 \%$ of the recorded orexin neurons receive input from LH/PF Vgat neurons (i.e., photo-evoked IPSCs in 71 of 116 recorded orexin neurons) and that approximately two-thirds of the light pulses evoked IPSCs in the synaptically connected neurons, indicating high-fidelity activation of the $\mathrm{LH} / \mathrm{PF}^{\text {Vgat }} \rightarrow$ Orx input. The $\mathrm{LH} / \mathrm{PF}^{\text {Vgat }} \rightarrow$ Orx input displayed paired pulse depression supporting a high probability of synaptic release in response to photostimulation (Debanne et al., 1996; Bonci and Williams, 1997).

The GABAergic neurons that give rise to the $\mathrm{LH} / \mathrm{PF}^{\text {Vgat }} \rightarrow$ Orx input are mainly located in the orexin field lateral to the fornix, medial to the optic tract and ventral to the zona incerta. Consistent with this anatomical distribution, a previous study identified small interneurons projecting to, and intermingled with, orexin neurons, although their neurotransmitter content was not known (Sakurai et al., 2005). Recent studies have shown that photostimulation of leptin receptor-expressing neurons (LepRb) in the lateral hypothalamus inhibits orexin neurons through GABA release (Bonnavion et al., 2015), suggesting that some of the LH/PF ${ }^{\text {Vgat }} \rightarrow$ Orx input that we photostimulated may have included LepRb neurons. Conversely, $\mathrm{MCH}$ neurons that have been shown to project to the orexin neurons (Guan et al., 2002) are an unlikely source of the $\mathrm{LH} / \mathrm{PF}^{\mathrm{Vgat}} \rightarrow$ Orx input, in particular because they appear to express little, if any, Vgat (Chee et al., 2015; Jennings et al., 2015; Herrera et al., 2017; Romanov et al., 2017). A recent study has demonstrated that stimulation of Lhx6 GABAergic neurons of the zona incerta promotes sleep by direct inhibition of orexin neurons (Liu et al., 2017). Because our AAV injections did not include the zona incerta, it is unlikely that we activated the same neurons. On the other hand, Lhx6 GABAergic neurons are also present in the lateral hypothalamus (Shimogori et al., 2010), but the question of whether the LH 
A
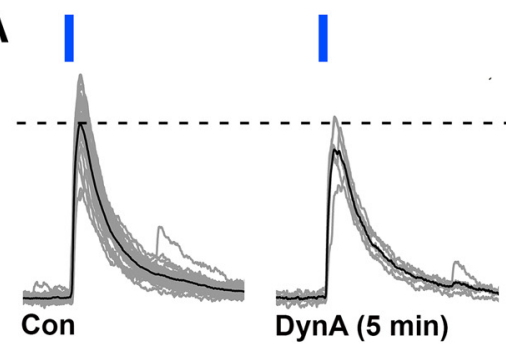

B

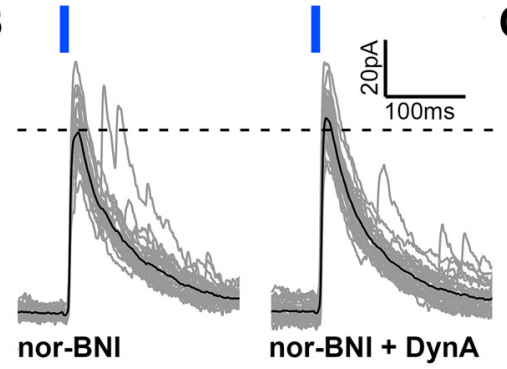

E

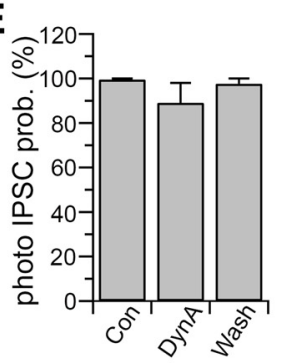

$\mathbf{F}$

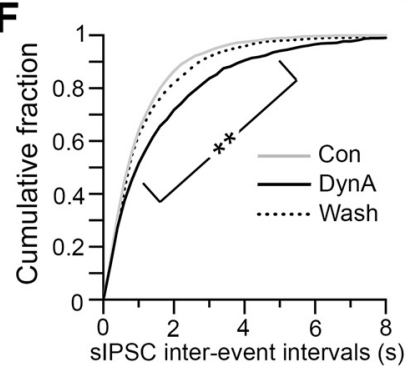

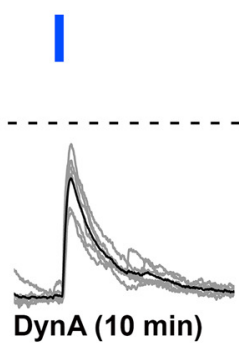

C
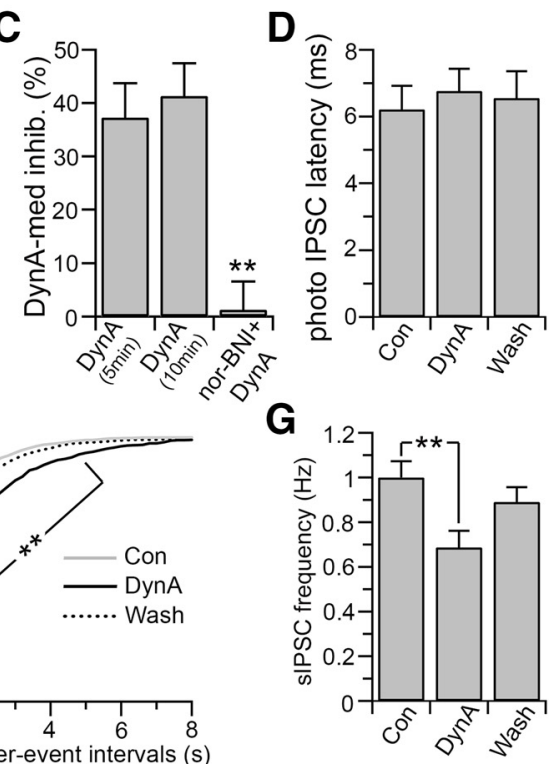

Figure 5. Effects of dynorphin on the LH/PF ${ }^{\mathrm{Vgat}} \rightarrow$ Orx input. $\boldsymbol{A}, \mathrm{DynA}(500 \mathrm{~nm})$ reduces the amplitude of the photo-evoked IPSCS, and this effect does not desensitize during $10 \mathrm{~min}$ DynA application. Con, 30 photo-evoked IPSCS recorded just before DynA application and average photo-evoked IPSC; DynA (5 min), 6 photo-evoked IPSCs recorded between 4 and 5 min of a $10 \mathrm{~min}$ DynA application and average photo-evoked IPSC; DynA (10 min), 6 photo-evoked IPSCs recorded between 9 and $10 \mathrm{~min}$ of a $10 \mathrm{~min}$ DynA application and average photo-evoked IPSC; wash, 30 photo-evoked IPSCS recorded after 10 min washout and average photo-evoked IPSCs. Gray represents individual photo-evoked IPSCs. Black represents average photo-evoked IPSCs. $\boldsymbol{B}$, The effect of DynA is abolished by the $\kappa$-opioid receptor antagonist nor-BNI $(1 \mu \mathrm{M})$. Gray represents 30 photo-evoked IPSCs. Black represents average photo-evoked IPSCS. C, Summary graph representing the DynA-mediated inhibition in control ACSF after 5 min application of DynA ( 5 min; $n=7)$, after 10 min application of Dyn-A (10 min; $n=7)$, and in the presence of nor-BNI (nor-BNI + DynA; $n=$ 5 , one-way ANOVA, $F=11.00, p=0.001$; Fisher's LSD post hoc test, ${ }^{* *} p<0.01$, comparing both DynA 5 min and DynA 10 min vs nor-BNI + DynA). $\boldsymbol{D}, \boldsymbol{E}$, DynA has no significant effect on the photo-evoked IPSC latency $(\boldsymbol{D}, n=7$; one-way ANOVA, $F=0.146$, $p=0.866)$, or photo-evoked probability $(\boldsymbol{E}, n=7$; one one-way ANOVA, $F=1.084, p=0.359) . \boldsymbol{F}, \boldsymbol{G}$, In the same orexin neurons in which DynA inhibits the LH/PF Vgat $\rightarrow$ Orx input, DynA also reduces the sIPSC frequency. Cumulative distribution plots of sIPSC interevent intervals compiled from 7 orexin neurons $(\boldsymbol{F} ; 200 \mathrm{~ms}$ bins; two-way ANOVA $F=4.606, p<0.001$; Bonferroni's multiple-comparisons post hoc test, ${ }^{* *} p<0.01$, comparing control and DynA). Mean values of the $\operatorname{SIPSC}$ frequency $(\boldsymbol{G} ; n=7$; one-way ANOVA, $F=4.956, p=0.019 ;{ }^{* *} p<0.01$, Fisher's LSD post hoc test). Photo-evoked IPSCs were evoked by $10 \mathrm{~ms}$ light pulses and were recorded at $V_{\mathrm{h}}=0 \mathrm{mV}$ using the Cs-methane-sulfonate-based pipette solution.

Lhx6 GABAergic neurons are sleep-promoting and project to orexin neurons will need further investigation.

\section{Regulation by cholinergic and peptidergic signaling}

The orexin field receives cholinergic afferent inputs (Sakai et al., 1990; Schäfer et al., 1998) that mainly originate from cholinergic neurons of the brainstem laterodorsal tegmental nucleus and pedunculopontine tegmental nucleus (Woolf and Butcher, 1986; Sakai et al., 1990; Kroeger et al., 2017). The projection from the basal forebrain, in contrast, mostly originates from glutamatergic and GABAergic inputs, with a minimum contribution from the cholinergic neurons (Gritti et al., 1994; Henny and Jones, 2006a,b; Agostinelli et al., 2017). Recent studies have also shown that the activity of brainstem cholinergic neurons strongly correlates with cortical fast activity of wakefulness and REM sleep, and activation of these neurons suppresses slow-wave EEG activity
(Boucetta et al., 2014; Kroeger et al., 2017). Furthermore, the firing rate of cholinergic laterodorsal tegmental nucleus/pedun-

culopontine tegmental nucleus neurons during active wakefulness, when fast $\gamma$ and $\theta$ EEG activities are high, is double that of quiet wakefulness (Boucetta et al., 2014). Because cholinergic signaling directly excites orexin neurons, it has been proposed that acetylcholine may facilitate the activation of orexin neurons during alert states (Bayer et al., 2005; Sakurai et al., 2005; Ohno et al., 2008; Zhou et al., 2015). We found that carbachol, through muscarinic receptors, depresses inhibitory input from local GABAergic neurons to orexin neurons ( $\mathrm{LH} / \mathrm{PF}^{\text {Vgat }} \rightarrow$ Orx $)$. We also found that cholinergic control of the GABAergic input to orexin neurons is input selective. Carbachol strongly depresses the $\mathrm{LH} / \mathrm{PF}^{\text {Vgat }} \rightarrow$ Orx input, whereas it has no significant effect on sIPSC frequency. This finding indicates that while most of the GABAergic input to orexin neurons is not affected by cholinergic signaling, the GABA input from local GABAergic neurons $\left(\mathrm{LH} / \mathrm{PF}^{\text {Vgat }} \rightarrow\right.$ Orx) is selectively and strongly inhibited. In addition, peak-scaled nonstationary fluctuation analysis indicates that carbachol inhibits local GABAergic input to orexin neurons by reducing the number of activated $\mathrm{GABA}_{\mathrm{A}}$ channels, but not the $\mathrm{GABA}_{\mathrm{A}}$ unitary current, supporting a presynaptic mechanism. We propose that, during wakefulness, release of acetylcholine activates orexin neurons through both a direct (Bayer et al., 2005; Sakurai et al., 2005) and an indirect mechanism (i.e., disinhibition by suppressing the local inhibitory circuit LH/PF ${ }^{\text {Vgat }} \rightarrow$ Orx).

A recent optogentic study reported that photostimulation of orexin neurons releases orexin, which in turn affects the activity of $\mathrm{MCH}$ neurons, providing important proof of concept that orexin neurons can control local circuits (Apergis-Schoute et al., 2015). Microdialysis studies showing that orexin levels in the LH are higher during active wakefulness than during NREM sleep (Kiyashchenko et al., 2002) provides further support for local release of orexin. We examined the effects of orexin-A specifically on the $\mathrm{LH} / \mathrm{PF}^{\text {Vgat }} \rightarrow$ Orx input. Unlike what we found with carbachol applications, orexin-A does not affect the $\mathrm{LH} / \mathrm{PF}^{\text {Vgat }} \rightarrow$ Orx input but increases the sIPSC frequency in orexin neurons. This finding suggests that, while the local GABAergic input to orexin neurons is not sensitive to orexin, other GABAergic inputs from unidentified origins are strongly enhanced by orexin signaling.

Orexin neurons also produce and corelease the endogenous opiate dynorphin (Chou et al., 2001; Torrealba et al., 2003; Crocker et al., 2005; Muschamp et al., 2014). Thus, it is conceivable that, like orexin, dynorphin is also locally released ( $\mathrm{Li}$ and van den Pol, 2006). Importantly, orexin and dynorphin are 


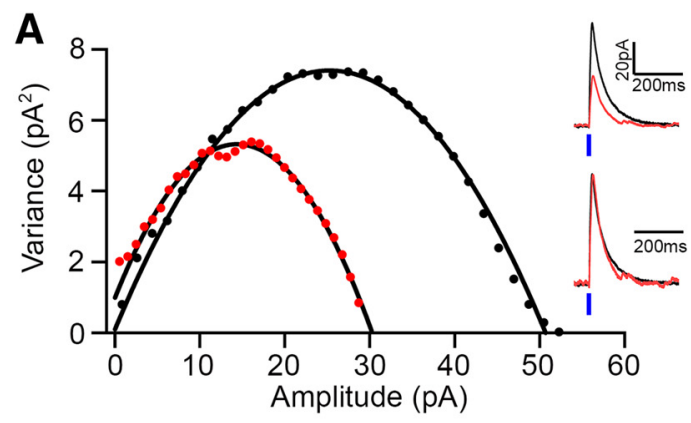

B
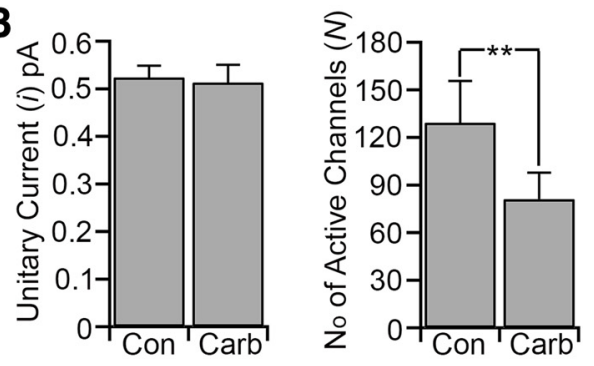

D

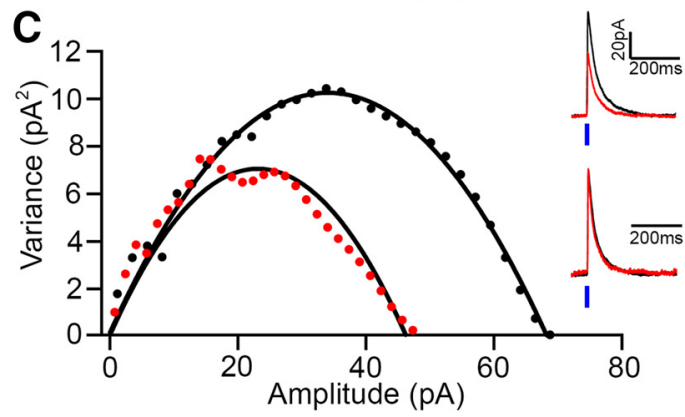

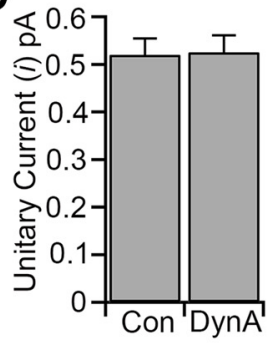

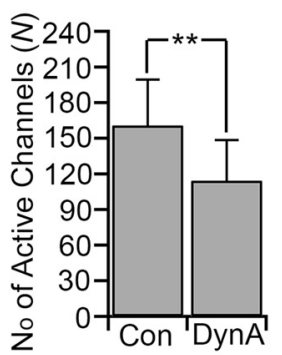

Figure 6. Carbachol and dynorphin reduce the number of $\mathrm{GABA}_{\mathrm{A}}$ receptor channels but not their unitary current. We used the peak-scaled nonstationary fluctuation analysis to assess whether carbachol and dynorphin inhibit the LH/PF Vgat $\rightarrow$ Orx input by reducing the unitary $\mathrm{GABA}_{A}$ current $(i)$ or the number of GABA $A_{A}$ receptors activated $(N)$. $A$, Left graph, Current/variance relationship for photo-evoked IPSCs. Black represents control. Red represents carbachol. Top traces, Superimposed average IPSCs. Bottom traces, Normalized IPSCs. $\boldsymbol{B}$, Summary plot of the mean GABA $A_{A}$ unitary current ( $n=8 ; p=0.64$, paired $t$ test) and mean number of $\mathrm{GABA}_{\mathrm{A}}$ receptor channels ( $n=8 ;{ }^{* *} p<0.01$ paired $t$ test) in control and carbachol. $C$, Left graph, Current/variance relationship for photo-evoked IPSCs. Black represents control. Red represents DynA. Top traces, Superimposed average IPSCs. Bottom traces, Normalized IPSCs. D, Summary plot of the mean GABA unitary current ( $n=8 ; p=0.34$, paired $t$ test) and mean number of $\mathrm{GABA}_{\mathrm{A}}$ receptor channels ( $n=8{ }^{* *} p<0.01$, paired $t$ test) in control and DynA.

known to produce opposite effects on their postsynaptic targets. Orexin, for example, excites postsynaptic neurons and increases synaptic inputs, whereas dynorphin inhibits postsynaptic neurons and synaptic inputs (Tallent, 2008; Bruchas and Chavkin, 2010; Kukkonen and Leonard, 2014). Similar complex actions by orexin and dynorphin have been found within the LH (Li et al., 2002; Li and van den Pol, 2006; Yamanaka et al., 2010; ApergisSchoute et al., 2015). In the present study, we found that orexin and dynorphin differentially affect GABAergic input from local GABAergic neurons to orexin neurons: orexin has no effect on $\mathrm{LH} / \mathrm{PF}^{\text {Vgat }} \rightarrow$ Orx input, whereas dynorphin acting through $\kappa$-opioid receptors strongly inhibits the $\mathrm{LH} / \mathrm{PF}^{\mathrm{Vgat}} \rightarrow$ Orx input. Compared with carbachol and orexin, DynA seems to produce a broader effect on the GABAergic input to orexin neurons. DynA depresses the $\mathrm{LH} / \mathrm{PF}^{\mathrm{Vgat}} \rightarrow$ Orx input and reduces sIPSC frequency in orexin neurons indicating that, in addition to the LH/ $\mathrm{PF}^{\mathrm{Vgat}} \rightarrow$ Orx input, other GABAergic inputs are depressed by dynorphin.

We also found that dynorphin action is likely presynaptic since, as we found for carbachol, dynorphin reduced the number of activated $\mathrm{GABA}_{\mathrm{A}}$ channels but not the $\mathrm{GABA}_{\mathrm{A}}$ unitary current. Analogously, previous work has shown that dynorphin in the $\mathrm{LH}$ inhibits the GABAergic afferent input to NPY neurons, and this effect is mediated by a presynaptic mechanism ( $\mathrm{Li}$ and van den Pol, 2006)

Dynorphin inhibits orexin neurons, and this effect quickly desensitizes (Li and van den Pol, 2006), whereas we found that dynorphin inhibits the $\mathrm{LH} / \mathrm{PF}^{\text {Vgat }} \rightarrow$ Orx input and this effect is unaltered throughout the duration of DynA application, suggesting that the $\kappa$-opioid receptors on the $\mathrm{LH} / \mathrm{PF}^{\text {Vgat }} \rightarrow$ Orx input do not desensitize or they only desensitize following longer exposures to DynA. Overall, our results indicate that local release of orexin and dynorphin produces a synergistic autoexcitation of orexin neurons. Specifically, orexin excites orexin neurons ( $\mathrm{Li}$ et al., 2002; Yamanaka et al., 2010), whereas dynorphin directly inhibits orexin neurons and concurrently disinhibits them by depressing inhibitory afferent inputs from local GABAergic neurons. While the direct inhibition of the orexin neurons by dynorphin quickly desensitizes ( $\mathrm{Li}$ and van den Pol, 2006), the dynorphin inhibition of the LH/PF ${ }^{\text {Vgat }} \rightarrow$ Orx is maintained. These results suggest that, when dynorphin is released, the disinhibitory effect may first be counterbalanced by direct inhibition, but over time, the disinhibitory effect of dynorphin might prevail.

There are several brain areas that contain both dynorphinexpressing neurons and neurons that project to the LH/PF region, including the following: the bed nucleus of the stria terminals, the central amygdala, the preoptic area, the arcuate, the dorsomedial hypothalamic nucleus, the ventromedial and the paraventricular nuclei of the hypothalamus, and in the brainstem the periaqueductal gray, laterodorsal tegmental nucleus, and lateral parabrachial nuclei (Merchenthaler et al., 1997; Yoshida et al., 2006). All of these regions send strong to moderate projections to the $\mathrm{LH} / \mathrm{PF}$ region, but it remains unclear what percentage of these inputs originate from dynorphin-expressing neurons. In summary, while dynorphin controls neuronal activity through presynaptic and postsynaptic effects (Chou et al., 2001; Li and van den Pol, 2006) and the orexin population is the likely source of dynorphin in the LH/PF region, we cannot exclude the possibility that LH/PF-projecting regions that contain dynorphin expressing neurons may also contribute to these responses.

\section{Physiological significance and neuronal circuitry controlling orexin neurons}

Lesions of the LH/PF region produce hypersomnia (Gerashchenko et al., 2003), whereas stimulation of this same region increases wakefulness for several hours (Alam and Mallick, 2008; Choudhary et al., 2014), strongly supporting a role for the LH/PF 
region in promoting arousal. Electrophysiological recordings and cFos studies have also revealed that a large number of neurons in this region are active during wakefulness (Estabrooke et al., 2001; Alam et al., 2002; Koyama et al., 2003; Lee et al., 2005), although there is also a substantial population of neurons that fire maximally during either NREM or REM sleep (Alam et al., 2002; Koyama et al., 2003; Hassani et al., 2010). These sleep-active neurons include $\mathrm{MCH}$ neurons (Hassani et al., 2009). However, the $\mathrm{MCH}$ neurons are only a small fraction, with the larger percentage of these sleep-active neurons being GABAergic and expressing Vgat (Hassani et al., 2010). In addition, cFos studies have found that many neurons in this region express cFos during rebound sleep after sleep deprivation or REM sleep deprivation (Verret et al., 2003, 2006; Modirrousta et al., 2005; Clément et al., 2012), and their anatomical distribution matches the location of the Vgat neurons that we transfected with ChR2.

Several lines of evidence support the hypothesis that, during sleep, orexin neurons are tonically inhibited by a strong GABAergic input. The finding that GABA levels in this region are higher during sleep compared with wakefulness is consistent with this hypothesis (Nitz and Siegel, 1996; Alam et al., 2005). In addition, blocking GABAergic signaling in the LH/PF activates orexin neurons and reverses the REM sleep-like state induced by carabachol injections into the pons, suggesting that orexin neurons are likely inhibited by a GABAergic input during REM sleep (Alam et al., 2005; Lu et al., 2007). We propose that GABAergic neurons in the $\mathrm{LH} / \mathrm{PF}$ region that are active in NREM and REM sleep suppress the activity of orexin neurons during these behavioral states. The GABAergic REM active neurons in the LH/PF region also innervate brainstem regions that are important for REM regulation (Verret et al., 2006; Clément et al., 2012). Thus, LH/PF REMactive GABAergic neurons can promote REM sleep through both descending projections to the brainstem and inhibition of surrounding orexin neurons.

Recent experimental work using optogenetic and chemogenetic tools has found that activation of LH/PF Vgat neurons arouses mice from NREM sleep (Herrera et al., 2016; Venner et al., 2016) and anesthesia (Herrera et al., 2016; Venner et al., 2016). These arousal effects are mediated through inhibition of the thalamic reticular nucleus or, possibly, sleep-active neurons of the ventrolateral preoptic area. These results suggest that GABAergic neurons comprise an important subpopulation of $\mathrm{LH} / \mathrm{PF}$ wake-promoting neurons. It is conceivable that there are at least two LH/PF Vgat neuronal populations with opposite behavioral state activities and separate efferent projections: one that is wake-active and suppresses the activity of sleep promoting regions, and one that is sleep-active and inhibits wake promoting neurons, including the orexin neurons. In support of this hypothesis, while optogenetic stimulation of LH Vgat terminals in the locus ceruleus arouses mice from NREM and REM sleep likely by disinhibiting noradrenergic locus ceruleus neurons (Herrera et al., 2016), LH neurons expressing both LepRb and galanin, which are putative Vgat-expressing neurons (Vong et al., 2011), project directly to noradrenergic locus ceruleus neurons (Laque et al., 2013). These results suggest potentially different roles of Vgat neurons in sleep versus wakefulness. More importantly, optogenetic activation of LH LepRb neurons delays the transition from sleep to wake (Herrera et al., 2016), supporting the possibility of a sleep-promoting subpopulation among LH Vgat neurons. Identification of additional cellular markers should permit the functional parsing of these two Vgat neuronal populations.

The GABAergic neurons in the LH comprise a complex population involved not only in sleep and wake regulation but also in reward, food intake, and behavioral food seeking (Bonnavion et al., 2016; Herrera et al., 2017). Interestingly, while optogenetic stimulation of LH Vgat neurons in NREM sleep promotes awakenings (Herrera et al., 2016), prolonged optogenetic stimulation of the same neurons during wakefulness produces increased food consumption (Jennings et al., 2015; Carus-Cadavieco et al., 2017). Recent work has also shown that, while chemogenetic activation of LH Vgat neurons increases both food-seeking and food-consumption behaviors, activation of LH galanin neurons, a subpopulation of Vgat LH neurons, increases food-seeking behavior but not overall increase in food intake (Qualls-Creekmore et al., 2017), suggesting another example of functional diversity among LH Vgat subpopulations. It is still unclear whether arousal and food seeking are functions regulated by the same or different Vgat populations. Additionally, as proposed recently, these two functions could operate in sequential order, first producing arousal and then eliciting food intake or in parallel, and in which case activation of the VGat neurons would simultaneously promote arousal, food seeking, and consumption (Herrera et al., 2017).

In conclusion, we have demonstrated that orexin neurons are inhibited by a local GABAergic input. This input is depressed by acetylcholine and dynorphin, but it is unaffected by orexin. We propose that this local GABAergic circuit inhibits orexin neurons during both NREM and REM sleep, whereas during wakefulness, orexin neurons are disinhibited by cholinergic input and by their own release of dynorphin. Local release of dynorphin regulates the $\mathrm{LH} / \mathrm{PF}^{\text {Vgat }} \rightarrow$ Orx circuit and may provide a positive feedback, through local collaterals, to orexin neurons.

\section{References}

Adamantidis AR, Zhang F, Aravanis AM, Deisseroth K, de Lecea L (2007) Neural substrates of awakening probed with optogenetic control of hypocretin neurons. Nature 450:420-424. CrossRef Medline

Agostinelli LJ, Ferrari LL, Mahoney CE, Mochizuki T, Lowell BB, Arrigoni E, Scammell TE (2017) Descending projections from the basal forebrain to the orexin neurons in mice. J Comp Neurol 525:1668-1684. CrossRef Medline

Alam MA, Mallick BN (2008) Glutamic acid stimulation of the perifornicallateral hypothalamic area promotes arousal and inhibits non-REM/REM sleep. Neurosci Lett 439:281-286. CrossRef Medline

Alam MN, Gong H, Alam T, Jaganath R, McGinty D, Szymusiak R (2002) Sleep-waking discharge patterns of neurons recorded in the rat perifornical lateral hypothalamic area. J Physiol 538:619-631. CrossRef Medline

Alam MN, Kumar S, Bashir T, Suntsova N, Methippara MM, Szymusiak R, McGinty D (2005) GABA-mediated control of hypocretin- but not melanin-concentrating hormone-immunoreactive neurones during sleep in rats. J Physiol 563:569-582. CrossRef Medline

Anaclet C, Pedersen NP, Ferrari LL, Venner A, Bass CE, Arrigoni E, Fuller PM (2015) Basal forebrain control of wakefulness and cortical rhythms. Nat Commun 6:8744. CrossRef Medline

Apergis-Schoute J, Iordanidou P, Faure C, Jego S, Schöne C, Aitta-Aho T, Adamantidis A, Burdakov D (2015) Optogenetic evidence for inhibitory signaling from orexin to $\mathrm{MCH}$ neurons via local microcircuits. J Neurosci 35:5435-5441. CrossRef Medline

Bayer L, Eggermann E, Serafin M, Grivel J, Machard D, Muhlethaler M, Jones BE (2005) Opposite effects of noradrenaline and acetylcholine upon hypocretin/orexin versus melanin concentrating hormone neurons in rat hypothalamic slices. Neuroscience 130:807-811. CrossRef Medline

Blouin AM, Thannickal TC, Worley PF, Baraban JM, Reti IM, Siegel JM (2005) Narp immunostaining of human hypocretin (orexin) neurons: loss in narcolepsy. Neurology 65:1189-1192. CrossRef Medline

Bonci A, Williams JT (1997) Increased probability of GABA release during withdrawal from morphine. J Neurosci 17:796-803. Medline

Bonnavion P, Jackson AC, Carter ME, de Lecea L (2015) Antagonistic interplay between hypocretin and leptin in the lateral hypothalamus regulates stress responses. Nat Commun 6:6266. CrossRef Medline

Bonnavion P, Mickelsen LE, Fujita A, de Lecea L, Jackson AC (2016) Hubs 
and spokes of the lateral hypothalamus: cell types, circuits and behaviour. J Physiol 594:6443-6462. CrossRef Medline

Boucetta S, Cissé Y, Mainville L, Morales M, Jones BE (2014) Discharge profiles across the sleep-waking cycle of identified cholinergic, GABAergic, and glutamatergic neurons in the pontomesencephalic tegmentum of the rat. J Neurosci 34:4708-4727. CrossRef Medline

Bruchas MR, Chavkin C (2010) Kinase cascades and ligand-directed signaling at the kappa opioid receptor. Psychopharmacology (Berl) 210:137147. CrossRef Medline

Burt J, Alberto CO, Parsons MP, Hirasawa M (2011) Local network regulation of orexin neurons in the lateral hypothalamus. Am J Physiol Regul Integr Comp Physiol 301:R572-R580. CrossRef Medline

Carus-Cadavieco M, Gorbati M, Ye L, Bender F, van der Veldt S, Kosse C, Börgers C, Lee SY, Ramakrishnan C, Hu Y, Denisova N, Ramm F, Volitaki E, Burdakov D, Deisseroth K, Ponomarenko A, Korotkova T (2017) Gamma oscillations organize top-down signalling to hypothalamus and enable food seeking. Nature 542:232-236. CrossRef Medline

Chee MJ, Arrigoni E, Maratos-Flier E (2015) Melanin-concentrating hormone neurons release glutamate for feedforward inhibition of the lateral septum. J Neurosci 35:3644-3651. CrossRef Medline

Chemelli RM, Willie JT, Sinton CM, Elmquist JK, Scammell T, Lee C, Richardson JA, Williams SC, Xiong Y, Kisanuki Y, Fitch TE, Nakazato M, Hammer RE, Saper CB, Yanagisawa M (1999) Narcolepsy in orexin knockout mice: molecular genetics of sleep regulation. Cell 98:437-451. CrossRef Medline

Chou TC, Lee CE, Lu J, Elmquist JK, Hara J, Willie JT, Beuckmann CT, Chemelli RM, Sakurai T, Yanagisawa M, Saper CB, Scammell TE (2001) Orexin (hypocretin) neurons contain dynorphin. J Neurosci 21:RC168. Medline

Choudhary RC, Khanday MA, Mitra A, Mallick BN (2014) Perifornical orexinergic neurons modulate REM sleep by influencing locus coeruleus neurons in rats. Neuroscience 279:33-43. CrossRef Medline

Chowdhury S, Yamanaka A (2016) Optogenetic activation of serotonergic terminals facilitates GABAergic inhibitory input to orexin/hypocretin neurons. Sci Rep 6:36039. CrossRef Medline

Clément O, Sapin E, Libourel PA, Arthaud S, Brischoux F, Fort P, Luppi PH (2012) The lateral hypothalamic area controls paradoxical (REM) sleep by means of descending projections to brainstem GABAergic neurons. J Neurosci 32:16763-16774. CrossRef Medline

Crocker A, España RA, Papadopoulou M, Saper CB, Faraco J, Sakurai T, Honda M, Mignot E, Scammell TE (2005) Concomitant loss of dynorphin, NARP, and orexin in narcolepsy. Neurology 65:1184-1188. CrossRef Medline

Debanne D, Guérineau NC, Gähwiler BH, Thompson SM (1996) Pairedpulse facilitation and depression at unitary synapses in rat hippocampus: quantal fluctuation affects subsequent release. J Physiol 491:163-176. CrossRef Medline

Dergacheva O, Yamanaka A, Schwartz AR, Polotsky VY, Mendelowitz D (2017) Optogenetic identification of hypothalamic orexin neuron projections to paraventricular spinally projecting neurons. Am J Physiol Heart Circ Physiol 312:H808-H817. CrossRef Medline

Estabrooke IV, McCarthy MT, Ko E, Chou TC, Chemelli RM, Yanagisawa M, Saper CB, Scammell TE (2001) Fos expression in orexin neurons varies with behavioral state. J Neurosci 21:1656-1662. Medline

Fuller PM, Sherman D, Pedersen NP, Saper CB, Lu J (2011) Reassessment of the structural basis of the ascending arousal system. J Comp Neurol 519: 933-956. CrossRef Medline

Gerashchenko D, Blanco-Centurion C, Greco MA, Shiromani PJ (2003) Effects of lateral hypothalamic lesion with the neurotoxin hypocretin-2saporin on sleep in Long-Evans rats. Neuroscience 116:223-235. CrossRef Medline

González JA, Iordanidou P, Strom M, Adamantidis A, Burdakov D (2016) Awake dynamics and brain-wide direct inputs of hypothalamic $\mathrm{MCH}$ and orexin networks. Nat Commun 7:11395. CrossRef Medline

Gritti I, Mainville L, Jones BE (1994) Projections of GABAergic and cholinergic basal forebrain and GABAergic preoptic-anterior hypothalamic neurons to the posterior lateral hypothalamus of the rat. J Comp Neurol 339:251-268. CrossRef Medline

Guan JL, Uehara K, Lu S, Wang QP, Funahashi H, Sakurai T, Yanagizawa M, Shioda S (2002) Reciprocal synaptic relationships between orexin- and melanin-concentrating hormone-containing neurons in the rat lateral hypothalamus: a novel circuit implicated in feeding regulation. Int J Obes Relat Metab Disord 26:1523-1532. CrossRef Medline

Hassani OK, Lee MG, Jones BE (2009) Melanin-concentrating hormone neurons discharge in a reciprocal manner to orexin neurons across the sleep-wake cycle. Proc Natl Acad Sci U S A 106:2418-2422. CrossRef Medline

Hassani OK, Henny P, Lee MG, Jones BE (2010) GABAergic neurons intermingled with orexin and $\mathrm{MCH}$ neurons in the lateral hypothalamus discharge maximally during sleep. Eur J Neurosci 32:448-457. CrossRef Medline

Henny P, Jones BE (2006a) Innervation of orexin/hypocretin neurons by GABAergic, glutamatergic or cholinergic basal forebrain terminals evidenced by immunostaining for presynaptic vesicular transporter and postsynaptic scaffolding proteins. J Comp Neurol 499:645-661. CrossRef Medline

Henny P, Jones BE (2006b) Vesicular glutamate (VGlut), GABA (VGAT), and acetylcholine (VACht) transporters in basal forebrain axon terminals innervating the lateral hypothalamus. J Comp Neurol 496:453-467. CrossRef Medline

Herrera CG, Cadavieco MC, Jego S, Ponomarenko A, Korotkova T, Adamantidis A (2016) Hypothalamic feedforward inhibition of thalamocortical network controls arousal and consciousness. Nat Neurosci 19:290-298. CrossRef Medline

Herrera CG, Ponomarenko A, Korotkova T, Burdakov D, Adamantidis A (2017) Sleep and metabolism: the multitasking ability of lateral hypothalamic inhibitory circuitries. Front Neuroendocrinol 44:27-34. CrossRef Medline

Hull C, Adesnik H, Scanziani M (2009) Neocortical disynaptic inhibition requires somatodendritic integration in interneurons. J Neurosci 29: 8991-8995. CrossRef Medline

Jennings JH, Ung RL, Resendez SL, Stamatakis AM, Taylor JG, Huang J, Veleta K, Kantak PA, Aita M, Shilling-Scrivo K, Ramakrishnan C, Deisseroth K, Otte S, Stuber GD (2015) Visualizing hypothalamic network dynamics for appetitive and consummatory behaviors. Cell 160:516-527. CrossRef Medline

Kiyashchenko LI, Mileykovskiy BY, Maidment N, Lam HA, Wu MF, John J, Peever J, Siegel JM (2002) Release of hypocretin (orexin) during waking and sleep states. J Neurosci 22:5282-5286. Medline

Kole MH, Letzkus JJ, Stuart GJ (2007) Axon initial segment Kvl channels control axonal action potential waveform and synaptic efficacy. Neuron 55:633-647. CrossRef Medline

Koyama Y, Takahashi K, Kodama T, Kayama Y (2003) State-dependent activity of neurons in the perifornical hypothalamic area during sleep and waking. Neuroscience 119:1209-1219. CrossRef Medline

Kroeger D, Ferrari LL, Petit G, Mahoney CE, Fuller PM, Arrigoni E, Scammell TE (2017) Cholinergic, glutamatergic, and GABAergic neurons of the pedunculopontine tegmental nucleus have distinct effects on sleep/wake behavior in mice. J Neurosci 37:1352-1366. CrossRef Medline

Kukkonen JP, Leonard CS (2014) Orexin/hypocretin receptor signalling cascades. Br J Pharmacol 171:314-331. CrossRef Medline

Laque A, Zhang Y, Gettys S, Nguyen TA, Bui K, Morrison CD, Münzberg H (2013) Leptin receptor neurons in the mouse hypothalamus are colocalized with the neuropeptide galanin and mediate anorexigenic leptin action. Am J Physiol Endocrinol Metab 304:E999-E1011. CrossRef Medline

Lee MG, Hassani OK, Jones BE (2005) Discharge of identified orexin/hypocretin neurons across the sleep-waking cycle. J Neurosci 25:6716-6720. CrossRef Medline

Li Y, van den Pol AN (2006) Differential target-dependent actions of coexpressed inhibitory dynorphin and excitatory hypocretin/orexin neuropeptides. J Neurosci 26:13037-13047. CrossRef Medline

Li Y, Gao XB, Sakurai T, van den Pol AN (2002) Hypocretin/orexin excites hypocretin neurons via a local glutamate neuron-A potential mechanism for orchestrating the hypothalamic arousal system. Neuron 36:11691181. CrossRef Medline

Liu K, Kim J, Kim DW, Zhang YS, Bao H, Denaxa M, Lim SA, Kim E, Liu C, Wickersham IR, Pachinis V, Hattar S, Song J, Brown SP, Blackshaw S (2017) Lhx6-positive GABA-releasing neurons of the zona incerta promote sleep. Nature 548:582-587. CrossRef Medline

Lu JW, Fenik VB, Branconi JL, Mann GL, Rukhadze I, Kubin L (2007) Disinhibition of perifornical hypothalamic neurones activates noradrenergic neurones and blocks pontine carbachol-induced REM sleep-like episodes in rats. J Physiol 582:553-567. CrossRef Medline 
Merchenthaler I, Maderdrut JL, Cianchetta P, Shughrue P, Bronstein D (1997) In situ hybridization histochemical localization of prodynorphin messenger RNA in the central nervous system of the rat. J Comp Neurol 384:211-232. CrossRef Medline

Mieda M, Hasegawa E, Kisanuki YY, Sinton CM, Yanagisawa M, Sakurai T (2011) Differential roles of orexin receptor-1 and -2 in the regulation of non-REM and REM sleep. J Neurosci 31:6518-6526. CrossRef Medline

Mileykovskiy BY, Kiyashchenko LI, Siegel JM (2005) Behavioral correlates of activity in identified hypocretin/orexin neurons. Neuron 46:787-798. CrossRef Medline

Mochizuki T, Crocker A, McCormack S, Yanagisawa M, Sakurai T, Scammell TE (2004) Behavioral state instability in orexin knock-out mice. J Neurosci 24:6291-6300. CrossRef Medline

Mochizuki T, Arrigoni E, Marcus JN, Clark EL, Yamamoto M, Honer M, Borroni E, Lowell BB, Elmquist JK, Scammell TE (2011) Orexin receptor 2 expression in the posterior hypothalamus rescues sleepiness in narcoleptic mice. Proc Natl Acad Sci U S A 108:4471-4476. CrossRef Medline

Modirrousta M, Mainville L, Jones BE (2005) Orexin and MCH neurons express c-fos differently after sleep deprivation vs recovery and bear different adrenergic receptors. Eur J Neurosci 21:2807-2816. CrossRef Medline

Momiyama A, Silver RA, Hausser M, Notomi T, Wu Y, Shigemoto R, CullCandy SG (2003) The density of AMPA receptors activated by a transmitter quantum at the climbing fibre-purkinje cell synapse in immature rats. J Physiol 549:75-92. CrossRef Medline

Muraki Y, Yamanaka A, Tsujino N, Kilduff TS, Goto K, Sakurai T (2004) Serotonergic regulation of the orexin/hypocretin neurons through the 5-HT1A receptor. J Neurosci 24:7159-7166. CrossRef Medline

Muschamp JW, Hollander JA, Thompson JL, Voren G, Hassinger LC, Onvani S, Kamenecka TM, Borgland SL, Kenny PJ, Carlezon WA Jr (2014) Hypocretin (orexin) facilitates reward by attenuating the antireward effects of its cotransmitter dynorphin in ventral tegmental area. Proc Natl Acad Sci U S A 111:E1648-E1655. CrossRef Medline

Nitz D, Siegel JM (1996) GABA release in posterior hypothalamus across sleep-wake cycle. Am J Physiol 271:R1707-R1712. Medline

Ohno K, Hondo M, Sakurai T (2008) Cholinergic regulation of orexin/ hypocretin neurons through $\mathrm{M}(3)$ muscarinic receptor in mice. J Pharmacol Sci 106:485-491. CrossRef Medline

Paxinos G, Franklin KB (2001) The mouse brain in stereotaxic coordinates, Ed 2. Cambridge, MA: Academic.

Petreanu L, Mao T, Sternson SM, Svoboda K (2009) The subcellular organization of neocortical excitatory connections. Nature 457:1142-1145. CrossRef Medline

Qualls-Creekmore E, Yu S, Francois M, Hoang J, Huesing C, Bruce-Keller A, Burk D, Berthoud HR, Morrison CD, Münzberg H (2017) Galaninexpressing GABA neurons in the lateral hypothalamus modulate food reward and noncompulsive locomotion. J Neurosci 37:6053-6065. CrossRef Medline

Robinson HP, Sahara Y, Kawai N (1991) Nonstationary fluctuation analysis and direct resolution of single channel currents at postsynaptic sites. Biophys J 59:295-304. CrossRef Medline

Romanov RA, Zeisel A, Bakker J, Girach F, Hellysaz A, Tomer R, Alpár A, Mulder J, Clotman F, Keimpema E, Hsueh B, Crow AK, Martens H, Schwindling C, Calvigioni D, Bains JS, Máté Z, Szabó G, Yanagawa Y, Zhang MD, et al. (2017) Molecular interrogation of hypothalamic organization reveals distinct dopamine neuronal subtypes. Nat Neurosci 20: 176-188. Medline

Saito YC, Tsujino N, Hasegawa E, Akashi K, Abe M, Mieda M, Sakimura K, Sakurai T (2013) GABAergic neurons in the preoptic area send direct inhibitory projections to orexin neurons. Front Neural Circuits 7:192. CrossRef Medline

Sakai K, Yoshimoto Y, Luppi PH, Fort P, el Mansari M, Salvert D, Jouvet M
(1990) Lower brainstem afferents to the cat posterior hypothalamus: a double-labeling study. Brain Res Bull 24:437-455. CrossRef Medline

Sakurai T, Nagata R, Yamanaka A, Kawamura H, Tsujino N, Muraki Y, Kageyama H, Kunita S, Takahashi S, Goto K, Koyama Y, Shioda S, Yanagisawa M (2005) Input of orexin/hypocretin neurons revealed by a genetically encoded tracer in mice. Neuron 46:297-308. CrossRef Medline

Sasaki K, Suzuki M, Mieda M, Tsujino N, Roth B, Sakurai T (2011) Pharmacogenetic modulation of orexin neurons alters sleep/wakefulness states in mice. PLoS One 6:e20360. CrossRef Medline

Scammell TE (2015) Narcolepsy. N Engl J Med 373:2654-2662. CrossRef Medline

Schäfer MK, Eiden LE, Weihe E (1998) Cholinergic neurons and terminal fields revealed by immunohistochemistry for the vesicular acetylcholine transporter: I. Central nervous system. Neuroscience 84:331-359. CrossRef Medline

Shimogori T, Lee DA, Miranda-Angulo A, Yang Y, Wang H, Jiang L, Yoshida AC, Kataoka A, Mashiko H, Avetisyan M, Qi L, Qian J, Blackshaw S (2010) A genomic atlas of mouse hypothalamic development. Nat Neurosci 13:767-775. CrossRef Medline

Shu Y, Yu Y, Yang J, McCormick DA (2007) Selective control of cortical axonal spikes by a slowly inactivating $\mathrm{K}^{+}$current. Proc Natl Acad Sci U S A 104:11453-11458. CrossRef Medline

Tallent MK (2008) Presynaptic inhibition of glutamate release by neuropeptides: use-dependent synaptic modification. Results Probl Cell Differ 44:177-200. CrossRef Medline

Torrealba F, Yanagisawa M, Saper CB (2003) Colocalization of orexin a and glutamate immunoreactivity in axon terminals in the tuberomammillary nucleus in rats. Neuroscience 119:1033-1044. CrossRef Medline

Traynelis SF, Silver RA, Cull-Candy SG (1993) Estimated conductance of glutamate receptor channels activated during EPSCs at the cerebellar mossy fiber-granule cell synapse. Neuron 11:279-289. CrossRef Medline

Venner A, Anaclet C, Broadhurst RY, Saper CB, Fuller PM (2016) A novel population of wake-promoting GABAergic neurons in the ventral lateral hypothalamus. Curr Biol 26:2137-2143. CrossRef Medline

Verret L, Goutagny R, Fort P, Cagnon L, Salvert D, Léger L, Boissard R, Salin P, Peyron C, Luppi PH (2003) A role of melanin-concentrating hormone producing neurons in the central regulation of paradoxical sleep. BMC Neurosci 4:19. CrossRef Medline

Verret L, Fort P, Gervasoni D, Léger L, Luppi PH (2006) Localization of the neurons active during paradoxical (REM) sleep and projecting to the locus coeruleus noradrenergic neurons in the rat. J Comp Neurol 495: 573-586. CrossRef Medline

Vong L, Ye C, Yang Z, Choi B, Chua S Jr, Lowell BB (2011) Leptin action on GABAergic neurons prevents obesity and reduces inhibitory tone to POMC neurons. Neuron 71:142-154. CrossRef Medline

Woolf NJ, Butcher LL (1986) Cholinergic systems in the rat brain: III. Projections from the pontomesencephalic tegmentum to the thalamus, tectum, basal ganglia, and basal forebrain. Brain Res Bull 16:603-637. CrossRef Medline

Yamanaka A, Beuckmann CT, Willie JT, Hara J, Tsujino N, Mieda M, Tominaga M, Yagami K, Sugiyama F, Goto K, Yanagisawa M, Sakurai T (2003) Hypothalamic orexin neurons regulate arousal according to energy balance in mice. Neuron 38:701-713. CrossRef Medline

Yamanaka A, Tabuchi S, Tsunematsu T, Fukazawa Y, Tominaga M (2010) Orexin directly excites orexin neurons through orexin 2 receptor. J Neurosci 30:12642-12652. CrossRef Medline

Yoshida K, McCormack S, España RA, Crocker A, Scammell TE (2006) Afferents to the orexin neurons of the rat brain. J Comp Neurol 494:845861. CrossRef Medline

Zhou WL, Gao XB, Picciotto MR (2015) Acetylcholine acts through nicotinic receptors to enhance the firing rate of a subset of hypocretin neurons in the mouse hypothalamus through distinct presynaptic and postsynaptic mechanisms. eNeuro 2:e0052. CrossRef Medline 